\title{
Aircraft viscous drag reduction using riblets
}

\author{
P.R. Viswanath* \\ Experimental Aerodynamics Division, National Aerospace Laboratories, Bangalore 560 017, India
}

\begin{abstract}
The last two decades have seen considerable research activity on the use of riblets for viscous drag reduction. Experimental results concerning the performance of $3 \mathrm{M}$ riblets on airfoils, wings and wing-body or aircraft configurations at different speed regimes are reviewed; these applications bring in additional effects like pressure gradients and three dimensionality. In addition to drag reduction, aspects of altered flow features due to riblets are discussed based on detailed wind tunnel measurements at low speeds. The available results obtained from wind tunnels as well as flight tests firmly establish the effectiveness of riblets from low speed to moderate supersonic Mach numbers. With optimized riblets, skin friction drag reduction in the range of 5-8\% have been measured on $2 \mathrm{D}$ airfoils at low incidence and in mild adverse pressure gradients; strong evidence exist at low speeds to indicate that riblets are more effective in adverse pressure gradients. On wings of moderate sweep relevant to transport aircraft, riblets remain effective providing drag reduction comparable to 2D airfoils, as long as the local angle between the surface streamlines and riblet orientation is relatively small $\left(<10^{\circ}\right)$. Limited data available on wing-body configurations show that total drag reduction of about $2-3 \%$ is likely. Certain suggestions for future research are outlined.
\end{abstract}

(C) 2002 Elsevier Science Ltd. All rights reserved.

\section{Contents}



2. Some general remarks on the experimental evaluation of drag reduction due to riblets . . . 574

3. Airfoils . . . . . . . . . . . . . . . . . . . . . . 574

3.1. Airfoils at low speeds. . . . . . . . . . . . . . . . . . . 574

3.2. NAL studies on airfoils at low speeds . . . . . . . . . . . . . . . . . 576

3.3. Low-speed studies on NACA 0012 and GAW-2 airfoils . . . . . . . . . . . . . . 577

3.3.1. Selection of riblets . . . . . . . . . . . . . . . . . . . 577

3.3.2. Drag performance with incidence . . . . . . . . . . . . . . . . . 577

3.3.3. Boundary layer development on the NACA 0012 airfoil . . . . . . . . . . . 579

3.3.4. Turbulence intensity profiles on the NACA 0012 airfoil . . . . . . . . . . 580

3.3.5. Reynolds shear stress profiles on the NACA 0012 airfoil and quadrant analysis 581

3.4. Airfoils at transonic speeds . . . . . . . . . . . . . . . . . 583



4.1. NAL studies on a swept wing with GAW-2 profile . . . . . . . . . . . . 586

4.1.1. Selection of riblets . . . . . . . . . . . . . . . . . 587

4.1.2. Drag performance with incidence . . . . . . . . . . . . . . . . 587

*Tel.: + 91-80-522-4024; fax: +91-80-522-3942.

E-mail addresses: vish@ead.cmmacs.ernet.in (P.R. Viswanath). 


\begin{tabular}{|c|c|c|c|}
\hline \multicolumn{2}{|c|}{ Nomenclature } & \multirow{2}{*}{\multicolumn{2}{|c|}{$\begin{array}{ll}-\left\langle u^{\prime} v^{\prime}\right\rangle & \text { r.m.s. value of Reynolds shear stress compo- } \\
& \text { nent in the streamwise direction } \\
u_{*} & \text { friction velocity }\end{array}$}} \\
\hline$c$ & airfoil/wing chord & & \\
\hline$C_{\mathrm{D}}$ & sectional drag coefficient $=\mathrm{drag}$ force $/\left(q_{\infty} * c\right)$ & $u^{+}$ & $u / u_{*}$ \\
\hline $\begin{array}{l}\Delta C_{\mathrm{D}} \\
C_{\mathrm{f}}\end{array}$ & $\begin{array}{l}C_{\mathrm{D} \text { rib }}-C_{\mathrm{D} \text { smooth }} \\
\text { skin friction coefficient }\end{array}$ & $x$ & $\begin{array}{l}\text { distance along the airfoil chord, from the } \\
\text { leading edge }\end{array}$ \\
\hline$\Delta C_{\mathrm{f}}$ & $C_{\mathrm{f} \text { rib }}-C_{\mathrm{f} \text { smooth }}$ & $y$ & distance normal to tunnel axis \\
\hline$C_{\mathrm{p}}$ & static pressure coefficient & $y^{+}$ & $y u * / v$ \\
\hline$C_{\mathrm{pb}}$ & base pressure coefficient, $\left(p_{\mathrm{b}}-p_{\infty}\right) / q_{\infty}$ & $z$ & distance in the spanwise direction \\
\hline & frequency, $\mathrm{Hz}$ & $\alpha$ & angle of attack \\
\hline$h$ & riblet height & $\beta$ & clauser pressure gradient parameter $=\left(\delta^{*} / \tau_{\mathrm{w}}\right)$ \\
\hline$h^{+}$ & $(\mathrm{hu} *) / v$ & & $(\mathrm{~d} p / \mathrm{d} x)$ \\
\hline$p$ & wall static pressure & $\beta^{+}$ & $\left(\theta / \tau_{\mathrm{w}}\right)(\mathrm{d} p / \mathrm{d} x)$ \\
\hline$p_{\infty}$ & freestream static pressure & $\delta$ & boundary layer thickness \\
\hline$q_{\infty}$ & freestream dynamic pressure & $\delta^{*}$ & boundary layer displacement thickness \\
\hline$R e_{\mathrm{c}}$ & reynolds number based on chord & $\tau_{\mathrm{w}}$ & wall shear stress \\
\hline$s$ & riblet spacing & $\varphi$ & local angle between surface streamline and \\
\hline$s^{+}$ & $\left(s u_{*}\right) / v$ & & riblet orientation (see Fig. 28), also referred \\
\hline$u$ & local mean velocity in streamwise direction & & to as riblet yaw angle \\
\hline$U_{\infty}$ & freestream velocity & $v$ & kinematic viscosity \\
\hline $\begin{array}{l}U_{\mathrm{e}} \\
\left\langle u^{\prime}\right\rangle\end{array}$ & $\begin{array}{l}\text { boundary layer edge velocity } \\
\text { r.m.s. value of velocity fluctuation in the } \\
\text { streamwise direction }\end{array}$ & & \\
\hline
\end{tabular}

4.1.3. Assessment of riblet yaw angle effects . . . . . . . . . . . . . . . . . 587

4.1.4. Boundary layer properties ahead of the trailing edge . . . . . . . . . . . 588

5. Flight investigations . . . . . . . . . . . . . . . . . . . . . . . 589

6. Wing-body and aircraft configurations . . . . . . . . . . . . . . . . . 591

7. Riblets at supersonic speeds . . . . . . . . . . . . . . . . . . . . . 592

8. Effect of riblets on lift characteristics . . . . . . . . . . . . . . . . . . . 593

9. Base drag reduction on airfoils $\ldots \ldots \ldots \ldots \ldots \ldots \ldots$



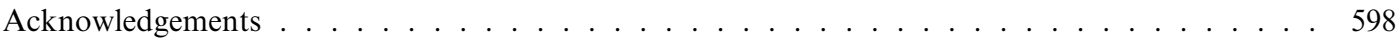

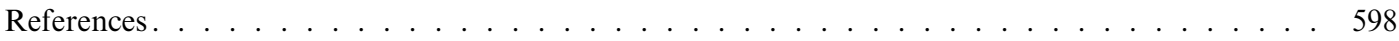

\section{Introduction}

Research on drag reduction methodologies relevant to flight vehicles has received considerable attention during the past 2-3 decades [1-6]. In the context of a civil or commercial transport aircraft, depending on the size, viscous or skin friction drag accounts for about $40-50 \%$ of the total drag under cruise conditions; the pay off is generally high even with a small level of drag reduction [7]. There has been continuous and focussed activity around the globe concerning development of new techniques for skin friction drag reduction [3,6] and attempts have progressed broadly in two directions: methods for delaying laminar-turbulent boundary layer transition and methods for altering or modifying the turbulent structure of a turbulent boundary layer. Passive techniques which have been extensively investigated for turbulent drag reduction include riblets and large eddy break-up (LEBU) devices. This review is concerned with riblets for transport aircraft 


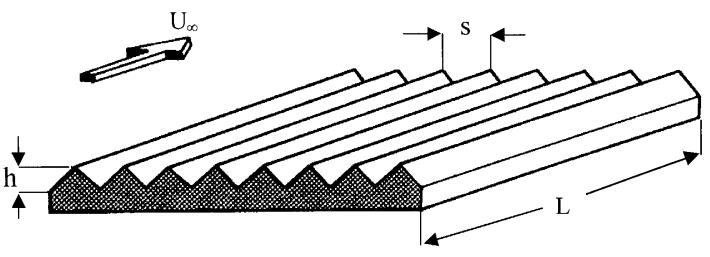

Fig. 1. Sketch of riblet geometry (taken from [7]).

applications. Over the years, extensive research on riblets has been carried out at the NASA Langley Research Centre (USA) and ONERA/CERT (France).

Riblets, which are micro-grooves on the surface and aligned to the freestream direction (Fig. 1), have been studied most extensively [8-10] and the results from these studies have been sufficiently promising and encouraging that the concept has been evaluated in flight tests. Several international meetings have addressed the subject of riblets, both from the view point of basic fluid mechanics as well as practical applications. Riblets with symmetric v-grooves (height equal to spacing) with adhesive backed film manufactured by the $3 \mathrm{M}$ company (USA) have been widely investigated in most earlier work and the results have revealed enormous consistency with regard to the degree of drag reduction as well as certain aspects of flow structure [8]. Maximum viscous drag reduction in the range of $4-8 \%$ has been measured on a variety of two-dimensional flows with zero or mild pressure gradients [8]; encouraged by these results, studies evaluating the effectiveness of riblets at transonic speeds as well as in flight [11-14] have been reported. A large body of data generated using $3 \mathrm{M}$ riblets reveal [8] that optimum drag reduction occurs in the range of $h^{+}\left(=h u_{*} / v\right)$ of $8-15$. Some of the earlier studies, e.g. Refs. [15,16], at low speeds have focussed attention on optimizing riblets geometry and drag reduction as high as $10 \%$ have been reported; however, their sensitivity to Mach number, incidence, yaw, etc., are not known at the present time.

In zero-pressure gradient flows, the effects of riblets appear to be confined to the near-wall region $\left(y^{+}<70\right)$. Despite world-wide research during the last 15 years, detailed mechanisms by which riblets reduce the wall shear stress are not clearly understood even in a zeropressure gradient boundary layer flow. Several mechanisms have been suggested which include: weakening of the bursting process near the wall [17], significant retardation of the flow in the groove valley dominated by viscous effects $[10,18]$, an increase in the sublayer thickness $[19,20]$, inhibition or restriction of spanwise motion of longitudinal vortices [19-21]; it is likely that many of the above flow features have their subtle role in altering the wall shear stress. Certain reduction in turbulence intensity and Reynolds shear stress in the wall region have also been reported by some of the investigators, e.g. $[8,18,22]$. Because of the relatively small groove dimensions (particularly with $3 \mathrm{M}$ riblets), measurements in the close vicinity of the grooves have been generally difficult. In the recent years, measurements of both mean velocity and some turbulence statistics in the grooves have become available [23,24] by using machine-cut riblets (of much higher dimensions than $3 \mathrm{M}$ ); these results show that wall shear stress is increased near groove peaks and appreciably reduced in the valley and it has been suggested $[23,24]$ that net drag reduction could result despite increased wetted area. Over the years, excellent review papers covering aspects of drag reduction and flow structure due to riblets have been published (Walsh [8] and Coustols and Savill [9]) and the most recent being that of Coustols [10].

Realistic applications involve pressure gradients, three dimensionality in addition to other factors and drag reduction under these conditions have been addressed, but not in sufficient detail. The boundary layer on an airfoil is subjected to combined influence of streamwise pressure gradients and surface curvature unlike the flow on a flat plate; wing sweep introduces three-dimensionality and spanwise gradients in addition. Despite technological interest, the effort that has been devoted to understanding the effectiveness of riblets in detail in the presence of these additional effects has been rather limited. There have been investigations substantiating drag reduction capabilities of riblets in pressure gradients [25-27]. The application of riblets on 2D airfoils at zero or low incidence has revealed viscous drag reduction comparable to zero-pressure gradient flows, e.g. $[11,28,29]$. Very encouraging results have been reported from wind tunnel tests on Do-228 aircraft model at low speeds [30] and Airbus A-320 wing-body model at transonic Mach numbers [11]. The flight experiments at relatively high Reynolds numbers on a T-33 [12] and Learjet airplanes [13] have provided considerable support to wind tunnel observations on riblets effectiveness. In view of the strong interest on the development of small transport aircraft in our laboratory, we initiated about 10 years ago, an active research programme on riblets with emphasis on assessing their effectiveness on aircraft components. Systematic experimental investigations on several airfoils and wings covering aspects of drag reduction and flow features due to riblets have been performed and results from many of these studies have been published [29,31-38].

This paper is a review of experimental results concerning the performance of $3 \mathrm{M}$ riblets on airfoils, wings and wing-body combinations in different speed regimes; aspects of riblet effectiveness in pressure gradients and three-dimensionality are discussed. In addition to drag reduction, aspects of altered flow features due to riblets are discussed based on detailed wind tunnel measurements at low speeds. Results from flight experiments (at relatively high Reynolds numbers) 
at subsonic, transonic and low supersonic Mach numbers are included. Effect of riblets on other design parameters like lift characteristics are discussed based on limited data available. Finally, certain suggestions for future research are outlined.

\section{Some general remarks on the experimental evaluation of drag reduction due to riblets}

Three different approaches have been employed in literature for the determination of viscous drag reduction arising from riblets. These are: (i) direct measurement of wall shear stress using a skin friction balance; (ii) use of $2 \mathrm{D}$ boundary layer momentum integral (MI) technique and (iii) use of an internal strain gauge balance (e.g. for bodies of revolution, wing-body configuration).

Direct measurement of wall shear stress using an accurate skin friction drag balance has been performed in several investigations and error bands have been estimated. The use of 2D MI involves measurement of velocity profiles in the boundary layer, both ahead and immediately downstream of the test surface, for the smooth as well as in the presence of riblets; this is usually accomplished using a pitot rake. The mean skin friction (over the test surface) is determined by calculating the change in boundary layer momentum thickness $(\theta)$ across the test surface. This method can provide satisfactory results provided the test surface is long enough to cause sufficient change in $\theta$. The application of MI for flows with streamwise pressure gradients involves the important assumption that the pressure field is virtually unaltered in the presence of riblets. There is reasonable evidence (e.g. on airfoils at low speeds) that changes in pressure distribution due to riblets are negligible as long as the boundary layer is attached and far from separating. Several studies have utilized the MI technique for the determination of the total drag of a 2D body (the classical wake survey method); this again involves measurement of velocity profiles in the wake (typically at 1-2 chord downstream of the trailing-edge) for the smooth body as well as with riblets. While the skin friction drag reduction can be obtained from total drag reduction (with the assumption that pressure drag does not change), estimate of percentage skin friction drag reduction would require knowledge of the pressure drag of the body. The use of an internal strain gauge balance for the measurement of total drag of a body is relatively straight forward; of course the balance output has to be properly corrected for internal forces, if any, to obtain the net drag force. Viscous drag reduction in percentage can be inferred from additional information on pressure drag.

As we shall see in later sections, despite the use of the three different techniques for drag reduction assessment, there is enormous consistency in the available data concerning the effectiveness of riblets in different speed regimes and flight experiments.

\section{Airfoils}

It is relevant and appropriate to briefly review early work on riblets in pressure gradients at low speeds before moving over to airfoil applications. In most studies, the magnitude of the pressure gradient is often described by the Clauser pressure gradient parameter $\beta$ $\left[=\left(\delta^{*} / \tau_{\mathrm{w}}\right)(\mathrm{d} p / \mathrm{d} x)\right]$. While $\beta$ can vary along the riblet surface, it has been convenient to define an average value of $\beta$ over the riblet surface (the averaging procedure used may vary in different studies); the average value of $\beta$ so defined is to be understood as a representative value for the given flow condition. Sometimes, the boundary layer momentum thickness, $\theta$, is used in place of $\delta^{*}$ and the pressure gradient parameter is defined here as $\beta^{+}$(see nomenclature).

Choi [39] investigated the effects of longitudinal pressure gradients on a flat plate with machined riblets (1.5 $\mathrm{mm}$ high and $2.5 \mathrm{~mm}$ pitch) for two values of pressure gradient parameter $\beta^{+}$of 3.1 and -0.16 at low speeds; the emphasis in the study was on the structure of near-wall turbulence but not on drag reduction. Based on measurements of mean velocity, streamwise turbulence intensity, wall shear stress fluctuations, he suggested that the effectiveness of riblets in reducing skin friction may remain under pressure gradients. The experiments carried out by Pulvin and Truong [25] in a channel flow showed maximum viscous drag reduction of about $6 \%\left(h^{+} \sim 13\right)$ for mild pressure gradients $(|\beta|<0.1)$, while the drag reduction was much lower at higher $\beta(0.20-1.90)$. Nieuwstadt et al. [27] measured drag reduction using a skin friction balance over a range of $\beta$ of $0.4-1.5$ at low speeds ; they used machined vgroove riblets (cut from PVC pipe) of size $h=s=0.64$ and $0.36 \mathrm{~mm}$. They observed skin friction drag reduction in the range of $4-7 \%$ (for $h=0.36 \mathrm{~mm}$ ) over the range of $\beta$ explored; the corresponding $h^{+}$range was $10-13$. These results provided support concerning the effectiveness of riblets in adverse pressure gradients; furthermore, an indication of a slight increase in drag reduction at higher $\beta$ was noted as well [27].

\subsection{Airfoils at low speeds}

Relevant experimental details and test conditions of earlier investigations performed on airfoil, wings and wing-body configurations are summarized in Table 1. Coustols and Cousteix [28] presented results of drag reduction on a $\mathrm{LC} 100 \mathrm{D}$ airfoil using $3 \mathrm{M}$ riblets at low speeds. Riblet sheets of $h=0.152$ and $0.076 \mathrm{~mm}$ were tested. With riblets covering only the airfoil upper 


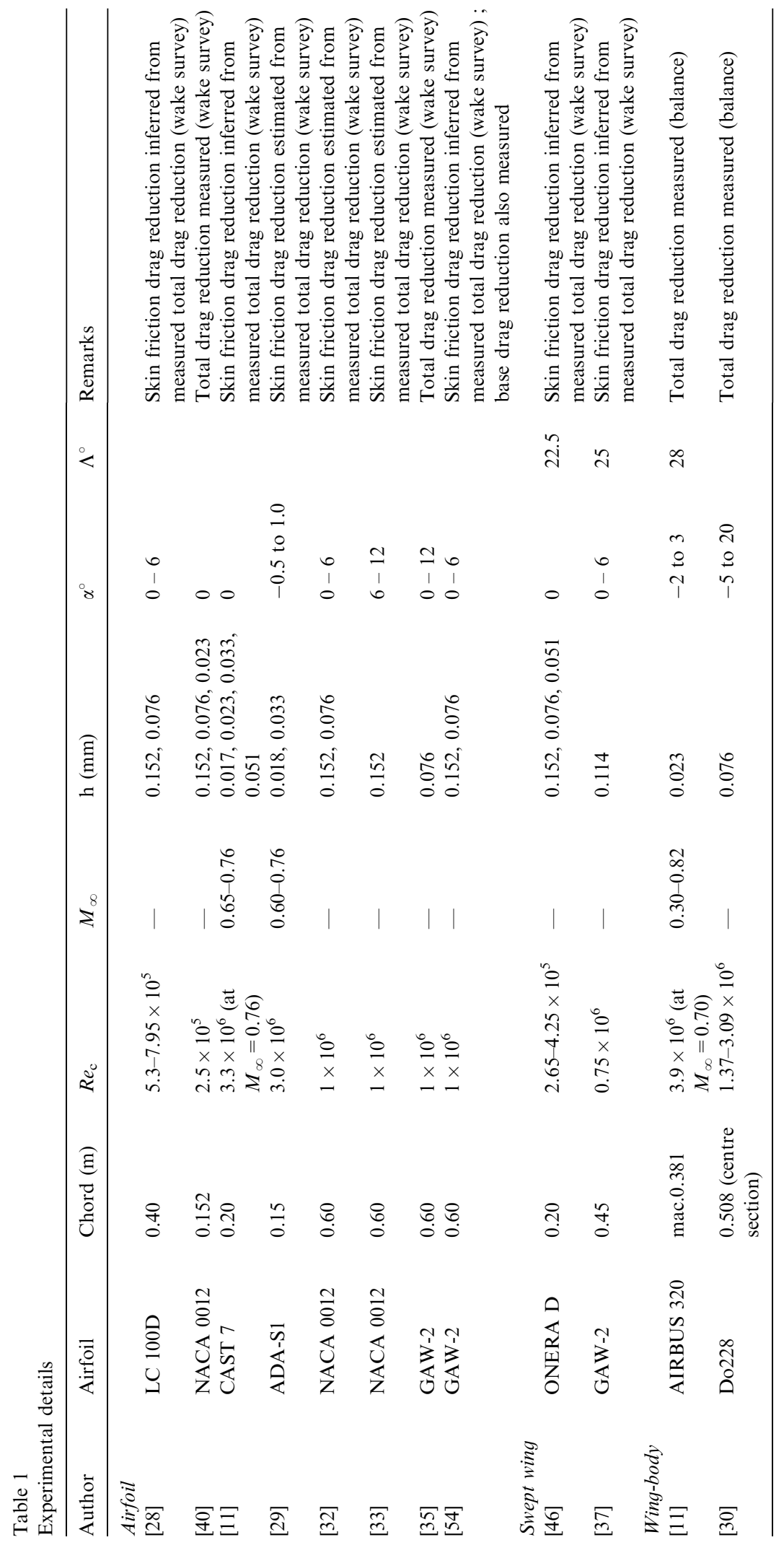




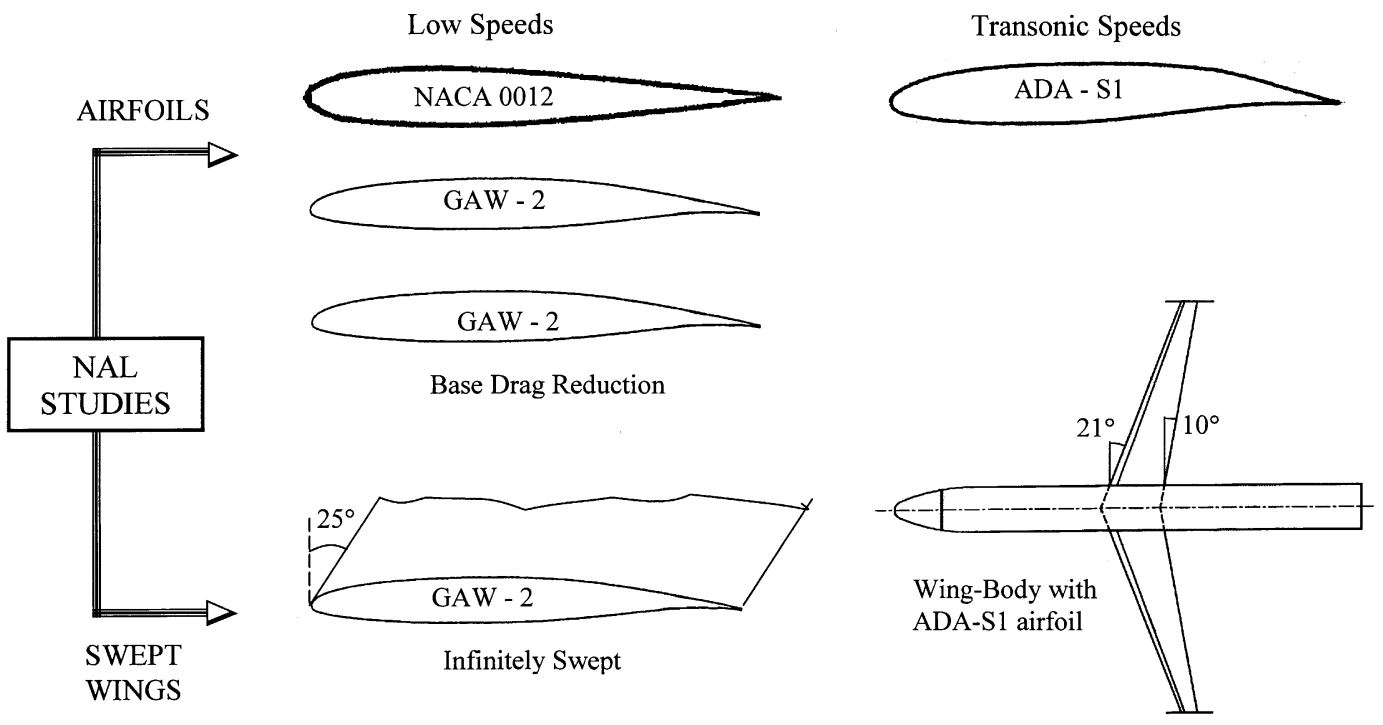

Fig. 2. Catalog of NAL experiments.

(or suction) surface, drag measurements were made using wake survey over an incidence range of $0-6^{\circ}$. They reported total drag reduction of about $2 \%$ at $\alpha=0^{\circ}$ and $2^{\circ}$, and no drag reduction at higher $\alpha$; the corresponding viscous drag reduction was estimated to be about $7 \%$. The poor performance of riblets at higher $\alpha$ was attributed partly to possible effects of boundary layer separation. Caram and Ahmed [40] studied the near and intermediate wake region of a NACA 0012 airfoil at zero incidence. They reported total drag reduction of $13.3 \%$ for $h=0.152 \mathrm{~mm}$ and lower reduction for other sizes $(2.7 \%$ and $7.3 \%$ for $h=0.076$ and $0.023 \mathrm{~mm}$, respectively); the total drag reduction of $13.3 \%$ and $7.3 \%$ which imply higher viscous drag reduction are much larger than the levels measured in zero or mild pressure gradient flows in literature; furthermore, the non-monotic variation of drag reduction with $h^{+}$raises some doubts on the accuracy of these measurements.

\subsection{NAL studies on airfoils at low speeds}

The limited data base from early studies on airfoils at zero and low incidence and flows subjected to mild adverse pressure gradients suggested that viscous drag reduction comparable to those observed in zero pressure gradient flows was likely. However, the available information on airfoils was inadequate to provide answers to many important issues: for example, effect of airfoil incidence on the performance of riblets, method for choosing optimum $h^{+}$for airfoil applications, etc. Furthermore, information on boundary layer properties on airfoils in the presence of riblets was generally lacking, even for a gross understanding of how the flow is altered.

Systematic investigations with $3 \mathrm{M}$ riblets were undertaken in our laboratory, both at low speeds and transonic speeds, on several airfoils and wings which are sketched in Fig. 2; certain broad experimental details are given in Table 1 . The experiments and analysis were relatively detailed on the NACA 0012 airfoil [31-33] covering an incidence range of $0-12^{\circ}$. The studies on the GAW(2) airfoil [34,35] were undertaken primarily to confirm certain new findings observed on the NACA 0012 airfoil. Riblet effectiveness at transonic speeds was assessed on a ADA-S1 supercritical airfoil [29].

In all the airfoil and wing configurations tested, the boundary layers on the upper and lower surfaces were tripped near the leading edge and the total drag was measured (both with and without riblets) using the wellknown wake survey method; two-dimensionality of the mean flow was first established using the 2D momentum integral equation technique. In all the cases, the riblets were applied typically over a streamwise distance of about $80 \%$ chord on both upper and lower surfaces. In cases, where the surface pressure distributions were measured, viscous drag reduction has been estimated based on total drag reduction and knowledge of pressure drag at each $\alpha$. The reference or baseline configuration for drag reduction assessment was always the smooth airfoil (without riblets) in the presence of the same boundary layer trip used with riblets. Furthermore, unlike in some of the earlier studies in literature, the smooth airfoil was not covered with plain plastic film (about $0.1 \mathrm{~mm}$ thick) to compensate for the riblet 
backing film while making drag comparisons; as a result, the measured drag reduction with riblets may be seen to be slightly conservative.

\subsection{Low-speed studies on NACA 0012 and $G A W-2$ airfoils}

The experiments on NACA 0012 airfoil [31-33] were performed in two phases using the same airfoil model having a chord of $0.60 \mathrm{~m}$. In the first phase, measurements covered an incidence range of $0-6^{\circ}$, and in addition to drag determination, measurements of mean velocity, turbulence intensity and Reynolds shear stress profiles were made in the boundary layer at selected locations on the airfoil; the second phase of experiments included primarily drag measurements in the incidence range of $8-12^{\circ}$ essentially to assess the drag reduction characteristics upto stall.

\subsubsection{Selection of riblets}

The selection of riblets was based on the correlation of viscous drag reduction with $h^{+}$which is now fairly well established for $3 \mathrm{M}$ riblets under zero-pressure gradient boundary layer flows (Fig. 3); the data reveal that maximum drag reduction occurs in the $h^{+}$range of about $8-15$ with the zero drag reduction cross over point around $h^{+} \sim 20$. A turbulent boundary layer code [41] based on the lag entrainment method of Green was utilized along with the measured pressure distributions on the airfoil to determine the streamwise variation of $h^{+}$at different $\alpha$; such results have been utilized to choose the optimum riblet height for a given flow condition.

Fig. 4 shows a sample of surface $C_{\mathrm{p}}$ distributions [32], both with and without riblets, measured on the NACA 0012 airfoil model at $\alpha=0^{\circ}$ and $6^{\circ}$; the effect of riblets on surface pressures was observed to be indeed small,

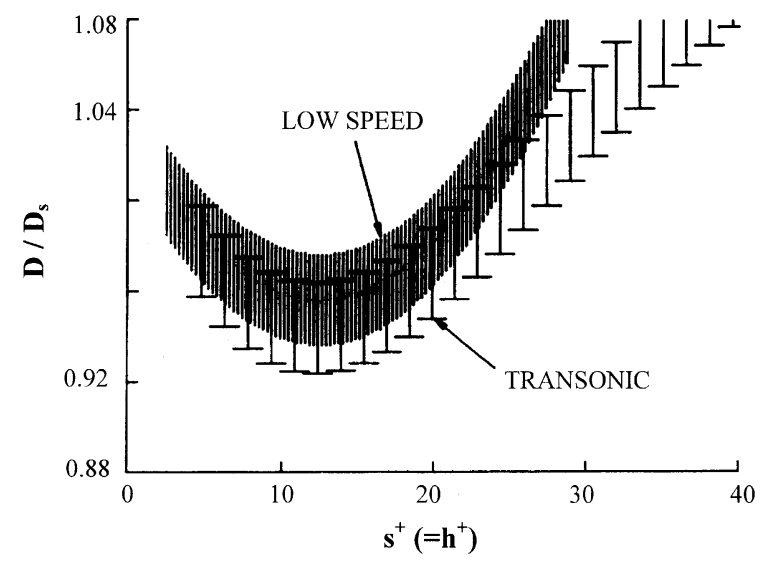

Fig. 3. Drag performance of riblets : $D$ and $D_{\mathrm{s}}$ are drag of riblet and smooth surface (taken from [8]).
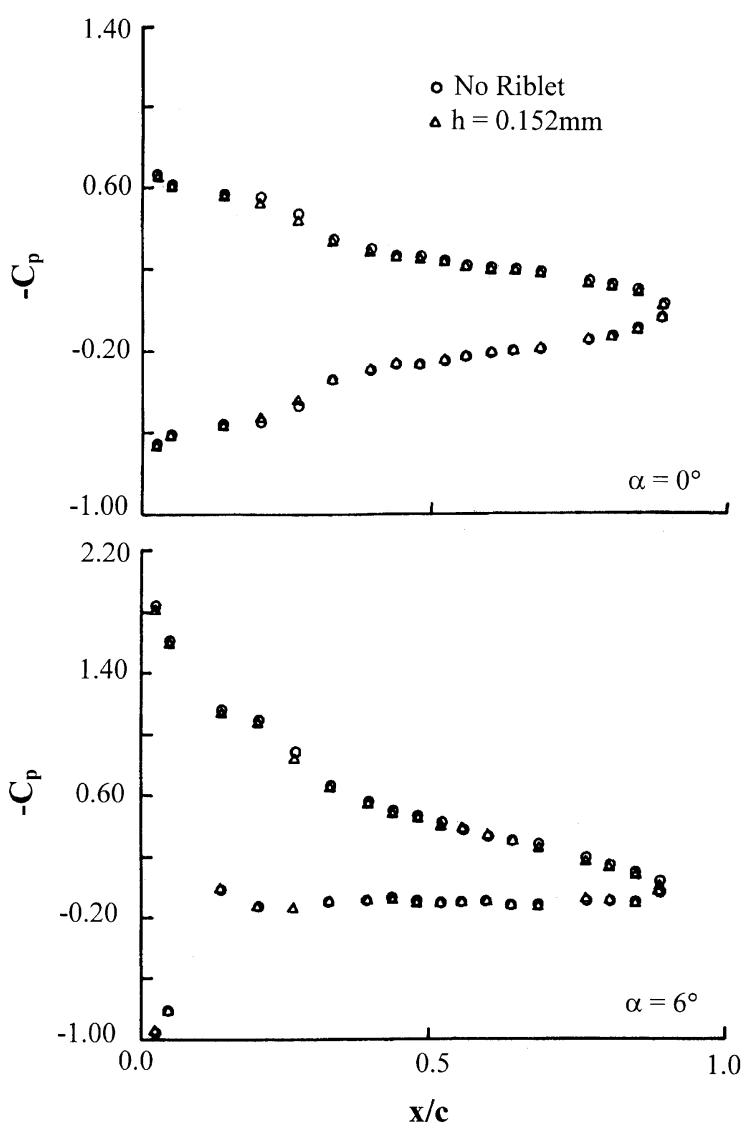

Fig. 4. Surface pressure distributions on NACA 0012 airfoil (taken from [32]).

as noted earlier by Coustols and Schmitt [11] on a supercritical airfoil at transonic speeds. As a consequence, the values of pressure drag were essentially the same (within a few percent) at a given $\alpha$ with generally no definite trend due to riblets.

The variation of $h^{+}$on the airfoil upper surface for the two extreme cases, namely, at $\alpha=0$ and $6^{\circ}$ are presented in Fig. 5 for three values of riblet height. The variations of $h^{+}$are well within the optimum range of $h^{+}$for $h=0.152 \mathrm{~mm}$; on the other hand, $h^{+}$variations for the riblet height of 0.114 and $0.076 \mathrm{~mm}$, although not within the optimum range, are still in the drag reduction range (Fig. 3). All the detailed measurements on the NACA 0012 were carried out with $h=0.152 \mathrm{~mm}$ [32].

\subsubsection{Drag performance with incidence}

Results of percentage total drag reduction (normalized by the drag value for the smooth airfoil at each $\alpha$ ) for the optimized riblets from Phase I and II experiments and the estimated values of percentage viscous drag reduction $\left(\Delta C_{\mathrm{f}} / C_{\mathrm{f}}\right)$ are shown in Fig. 6 ; the variation of the Clauser pressure gradient parameter $(\beta)$ for the airfoil upper surface is also included in the 


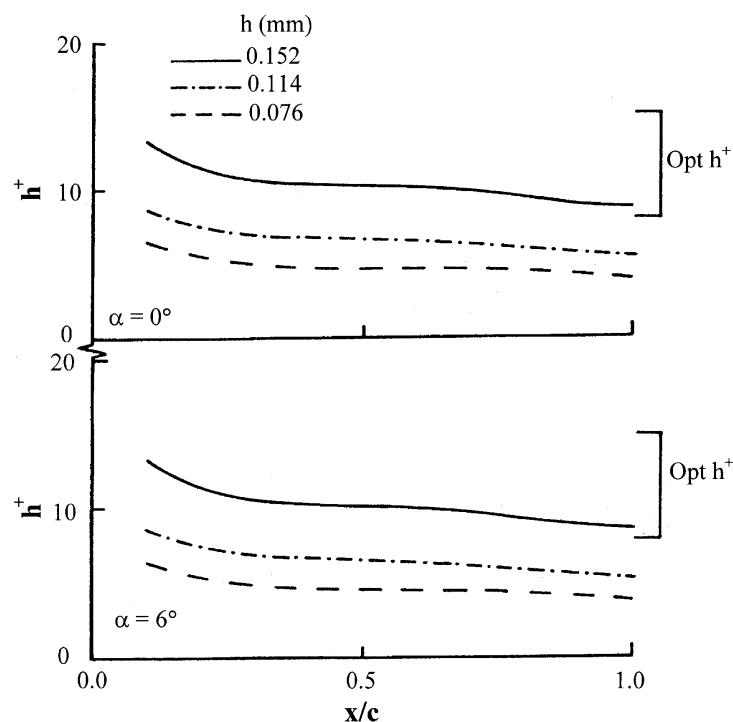

Fig. 5. Variations of $h^{+}$on upper surface, NACA 0012 airfoil (taken from [32]).
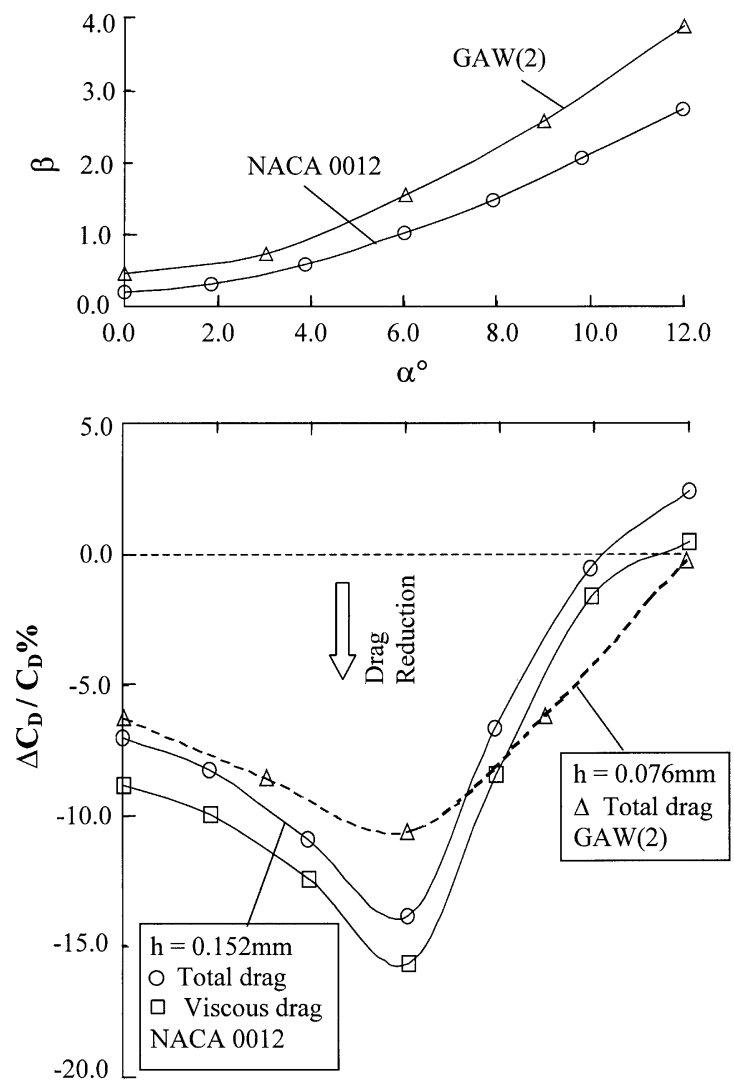

Fig. 6. Variations of drag reduction and Clauser parameter with incidence. above figure. Since in general, $\beta$ varies along the airfoil chord, what is presented above is an average (or representative) value for each $\alpha$ estimated mid-way in the adverse pressure gradient region $(0.4 \leqslant x / c \leqslant 0.95)$ with the values of $\delta^{*}$ and $\tau_{\mathrm{w}}$ calculated from the lag entrainment boundary layer code [41].

The total drag reduction increased initially with incidence from about $7 \%$ at $\alpha=0^{\circ}$ to $13 \%$ at $\alpha=6^{\circ}$, beyond which there was a gradual decrease to virtually no drag reduction around $\alpha=10^{\circ}$; the maximum skin friction drag reduction was as high as $16 \%$ at $\alpha=6^{\circ}$ and the corresponding value of $\beta$ was about 1.06 . The above observation, for the first time, was suggestive that drag reduction due to riblets can increase with incidence unlike earlier findings where the trend with $\alpha$ was opposite. At higher $\alpha\left(\geqslant 6^{\circ}\right)$, although $\beta$ increased monotically with $\alpha$, drag reduction fell gradually due to the progressive deceleration of the upper surface boundary layer leading eventually to separation. By measuring the mean velocity profiles just ahead of the trailing edge $(x / c=0.964)$ on the airfoil upper and lower surfaces (an example at $\alpha=4^{\circ}$ shown in Fig. 7), Sundaram et al. [31,32] demonstrated that the airfoil suction side contributed significantly to the increased drag reduction with $\alpha$, providing strong evidence that riblets can be more effective in adverse pressure gradients.

In order to confirm that the initial trend of increased drag reduction with $\alpha$ was not a feature associated with

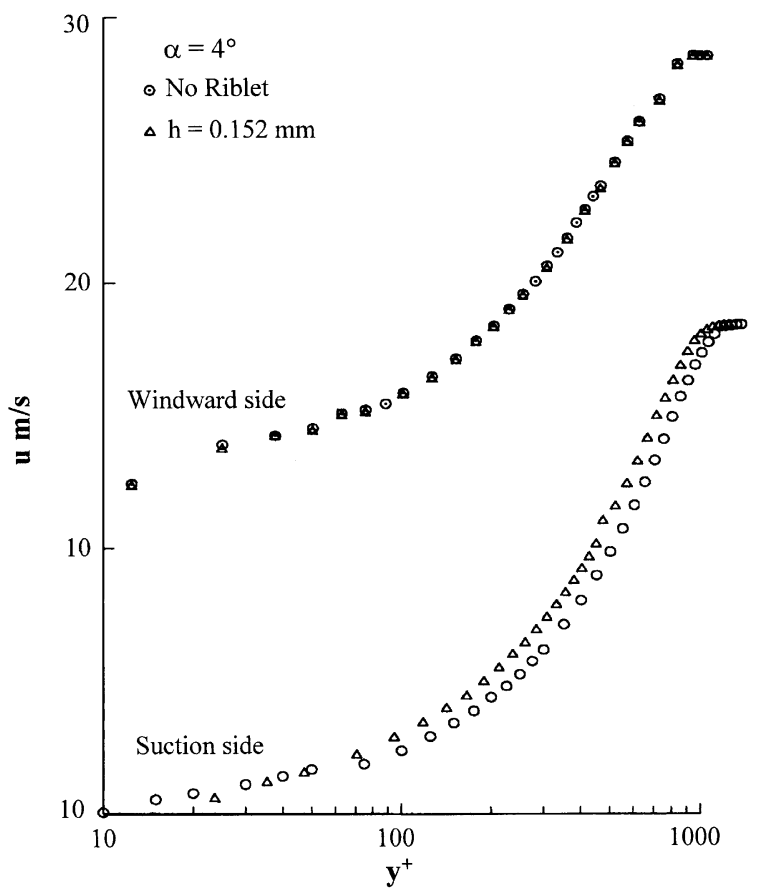

Fig. 7. Mean velocity profile at $x / c=0.964$, NACA 0012 airfoil. 
the symmetric airfoil section (NACA 0012) used and to study the behaviour of riblets on a cambered airfoil, additional experiments [34-35] were carried out on a GAW-2 airfoil in the same wind tunnel, instrumentation and similar test conditions; only total drag measurements were made for the riblet size of $0.076 \mathrm{~mm}$. The results, included in Fig. 6, showed the same qualitative behaviour as the NACA 0012; maximum total reduction of $10 \%$ occurred at $\alpha=6^{\circ}$ with a value of $\beta$ around 1.50 . It is interesting that both the airfoils tested reflect peak drag reduction around $\alpha=6^{\circ}$ which is essentially a feature associated with the test conditions of the experiments and Reynolds number in particular; at higher Reynolds numbers, the maximum drag reduction may be expected to shift to a higher $\alpha$. Significant retardation of the near-wall flow arising from progressively increasing adverse pressure gradient with $\alpha$ may be expected to limit the maximum effectiveness of riblets on an airfoil.

Additional support to the main finding of increased drag reduction in adverse pressure gradients is provided by the experimental results of Debisschop and Nieuwstadt [42] on a flat plate boundary layer with imposed adverse pressure gradients at low speeds. A specially designed skin friction drag balance was used in the experiments. For both v-groove $(h=s)$ and trapezoidal groove $(h=0.5 \mathrm{~s})$ riblets (manufactured from PVC pipes), skin friction drag reduction in the range of 12 $13 \%$ (corresponding $h^{+}$being 10-16 for v-groove) was observed at a value of $\beta=2.20$ (Fig. 8). They also concluded that the effectiveness of riblets increases in

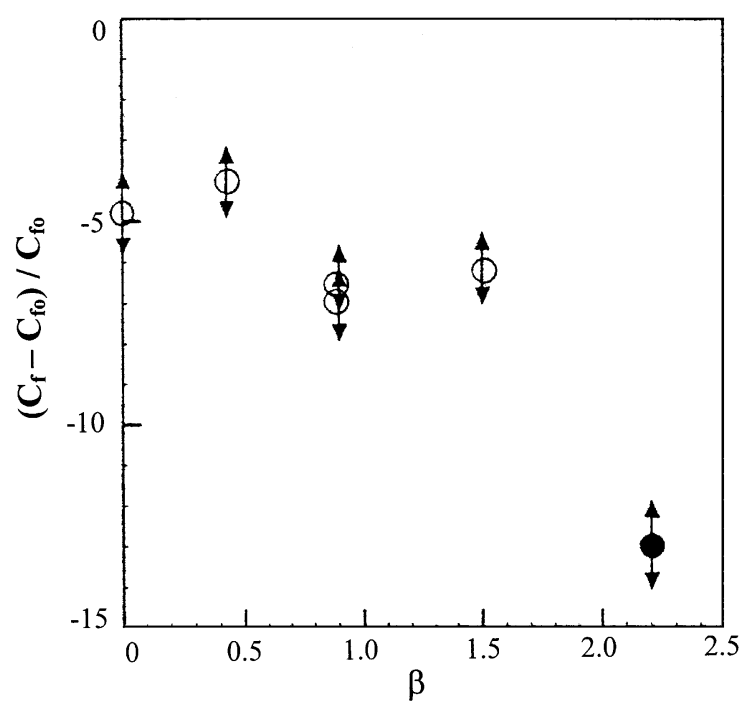

Fig. 8. Evolution of relative skin friction vs pressure gradient; open symbols, experiments by Nieuwstadt et al, 1993; closed symbol, Debisshop and Nieuwstadt 1996 (taken from Debisshop and Nieuwstadt, 1996). adverse pressure gradients [42]; these results also suggest that the increased effectiveness is not limited to vgrooves with $h=s$.

The possible role of convex surface curvature on riblet effectiveness on the NACA 0012 results was discussed by Sundaram et al. [32]. The surface curvature is identical on the upper and lower surfaces because of symmetry; however, the curvature effects will in general be different due to differing boundary layer growth. The combined effects of streamwise convex surface curvature and mild pressure gradients on the airfoil lower surface was found to be small from the point of view of drag reduction as seen from Fig. 7. Furthermore, on the airfoil upper surface, the effective streamline curvature is likely to be smaller because of streamline divergence due to adverse pressure gradients. Sundaram et al. [32] indicated that the adverse pressure gradient on the airfoil upper surface was a dominant factor resulting in increased viscous drag reduction on a riblet surface. It would be of significant value to assess riblet effectiveness on a convex wall in a zero pressure gradient flow in future experiments.

\subsubsection{Boundary layer development on the NACA 0012 airfoil}

Sundaram et al. [32] examined the effects of riblets on mean flow development in the boundary layer on the airfoil. Velocity profiles, measured at two $x / c$ values of $0.25 c$ and $0.50 c$ on the airfoil upper surface at $\alpha=4^{\circ}$, are shown in Fig. 9 [32]. The velocities are higher (for $y^{+} \geqslant 20$ ) with riblets and an increased intercept in the log-law associated with the thickening of the sublayer is seen; this is a feature well known in zero pressure gradient flows $[8,19,20]$. Boundary layer profiles measured just ahead of the trailing edge $(x / c=0.964)$ on the upper surface at $\alpha=0^{\circ}, 4^{\circ}$ and $6^{\circ}$ are displayed in Fig. 10. The profiles at $\alpha=0^{\circ}$ and $4^{\circ}$ showed features similar to those discussed above except that the values of $A$ and $B$ in the log-law were slightly different. At $\alpha=6^{\circ}$ on the other hand, a decreased intercept with riblets (from 4.93 to 2.10 ) was observed with the slope $A$ remaining the same: for this case, the lower intercept was caused not by an increase in $C_{\mathrm{f}}$ or $\tau_{\mathrm{w}}$ (as one may guess), but from lower mean velocities for $y^{+} \leqslant 200$ as may be seen from Fig. 11 (in contrast to higher velocities observed generally); the lower mean velocities are obviously a result of higher adverse pressure gradient. The wall friction velocity is still lower with riblets at $\alpha=6^{\circ}$ (Fig. 12) and is associated with maximum viscous drag reduction on the NACA 0012 airfoil. In the experiments of Debisschop and Nieuwstadt [42] an increased intercept was observed at $\beta=2.20$ for which a skin friction drag reduction of about $13 \%$ with v-grooves was recorded. 


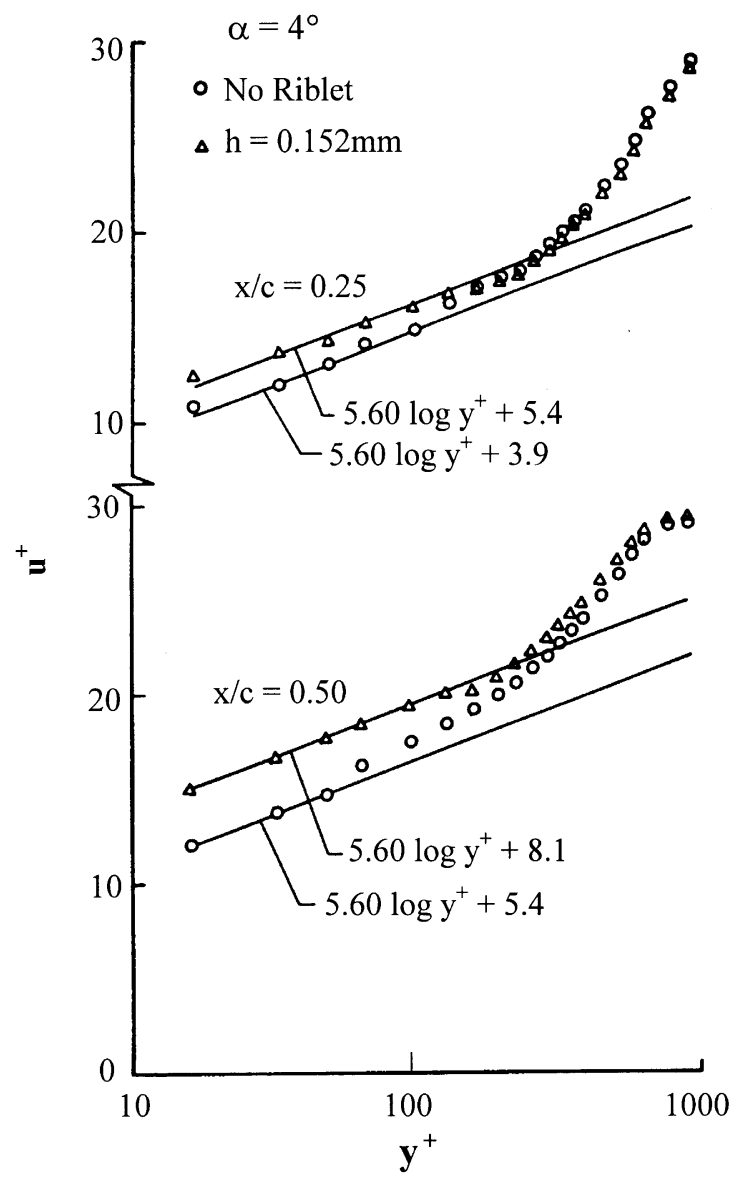

Fig. 9. Mean velocity profiles on upper surface at $\alpha=4^{\circ}$, NACA 0012 airfoil (taken from [32]).

\subsubsection{Turbulence intensity profiles on the NACA 0012 airfoil}

Streamwise turbulence intensity $\left\langle u^{\prime}\right\rangle$ and Reynolds shear stress $\left\langle u^{\prime} v^{\prime}\right\rangle$ profiles were measured, both with and without riblets, on the airfoil upper surface at $x / c=0.964$ so that one could observe the cumulative effects of riblets over the airfoil surface. Results of $\left\langle u^{\prime}\right\rangle$ profiles at $\alpha=0^{\circ}$ and $6^{\circ}$ corresponding to $\beta=0.20$ and 1.06 are shown in Fig. 13a (results at $\alpha=2^{\circ}$ and $4^{\circ}$ may be seen in Ref. [32]); the influence of riblets is not confined just to the near-wall region with increase in $\beta$ (e.g. upto $y^{+} \sim 300$ at $\alpha=6^{\circ}$ ). On the riblet surface, a reduction in $\left\langle u^{\prime}\right\rangle$ in the range of $10-15 \%$ was observed [32] for $y^{+} \leqslant 100$ at $\alpha=0^{\circ}, 2^{\circ}$ and $4^{\circ}$, while such a reduction was limited to $y^{+} \sim 40$ at $\alpha=6^{\circ}$; furthermore, an increase in $\left\langle u^{\prime}\right\rangle$ in the mid-part of the boundary layer was observed at $\alpha=6^{\circ}$, possibly indicating the effect of larger $\beta$ for this case. Typical spectra of $u^{\prime}$ fluctuation measured near the wall $\left(y^{+} \sim 20\right)$ at $\alpha=0^{\circ}$ and $6^{\circ}$ showed (Fig. 13b) reduced energy levels at low frequencies (below $200 \mathrm{~Hz}$ ) on the riblet surface. The

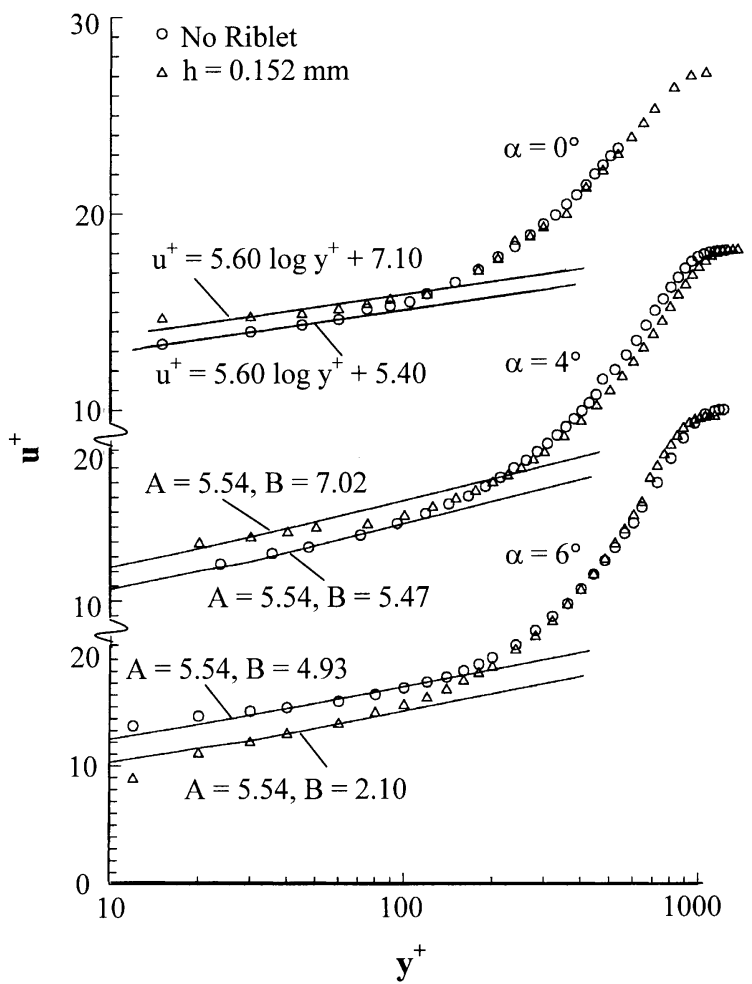

Fig. 10. Mean velocity profiles on upper surface at $x / c=0.964$, NACA 0012 airfoil.

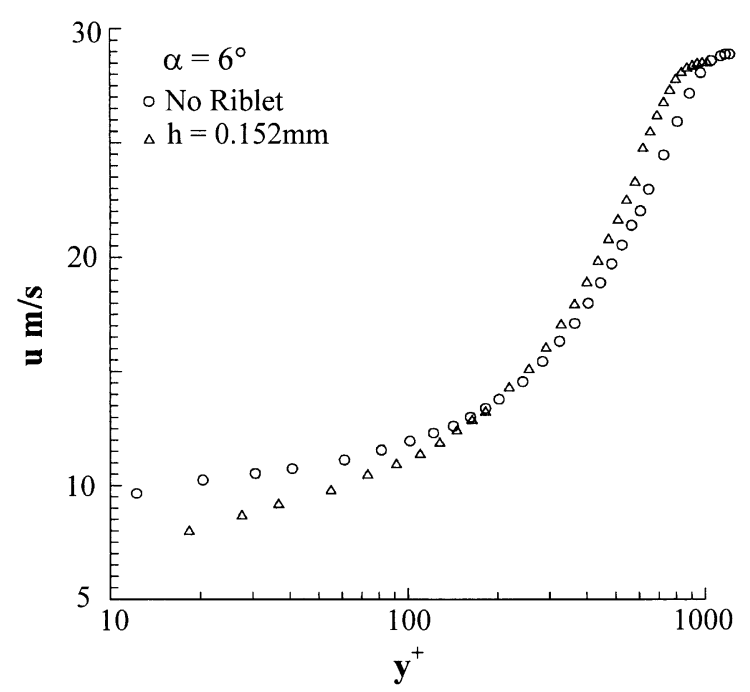

Fig. 11. Mean velocity profiles on upper surface at $x / c=0.964$, and $\alpha=6^{\circ}$, NACA 0012 airfoil.

above features of $u^{\prime}$ fluctuation suggest that the influence of riblets in adverse pressure gradients (for $\beta<1.06$ ) are qualitatively similar to those observed in zero pressure gradient boundary layer flows $[8,19]$. 


\subsubsection{Reynolds shear stress profiles on the NACA 0012} airfoil and quadrant analysis

Normalized turbulent shear stress profiles at $x /$ $c=0.964$ on the airfoil upper surface at $\alpha=0^{\circ}$ and $6^{\circ}$ are presented in Fig. 14; only a marginal reduction in < $\left.u^{\prime} v^{\prime}\right\rangle$ values was seen on the riblet surface at $\alpha=0^{\circ}$. At $\alpha=6^{\circ}(\beta \sim 1.06)$, a noticeable reduction in $\left\langle u^{\prime} v^{\prime}\right\rangle$ on the riblet surface was observed and over a large fraction of

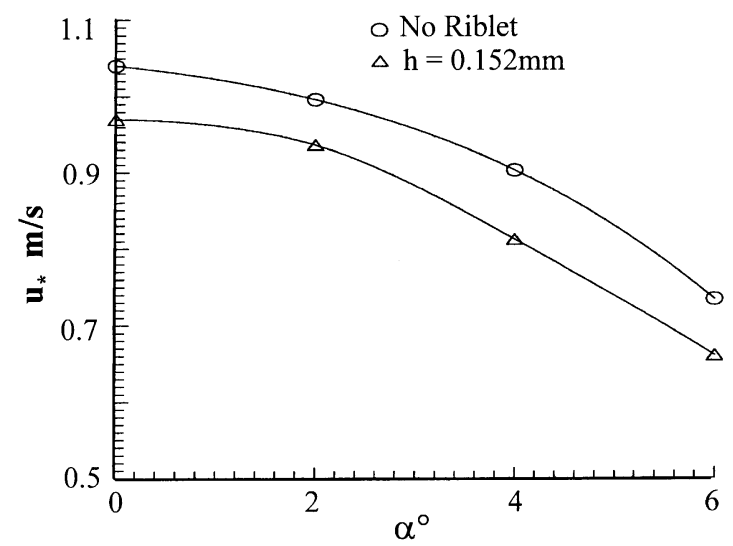

Fig. 12. Variation of friction velocity on upper surface at $x / c=0.964$, NACA 0012 airfoil.
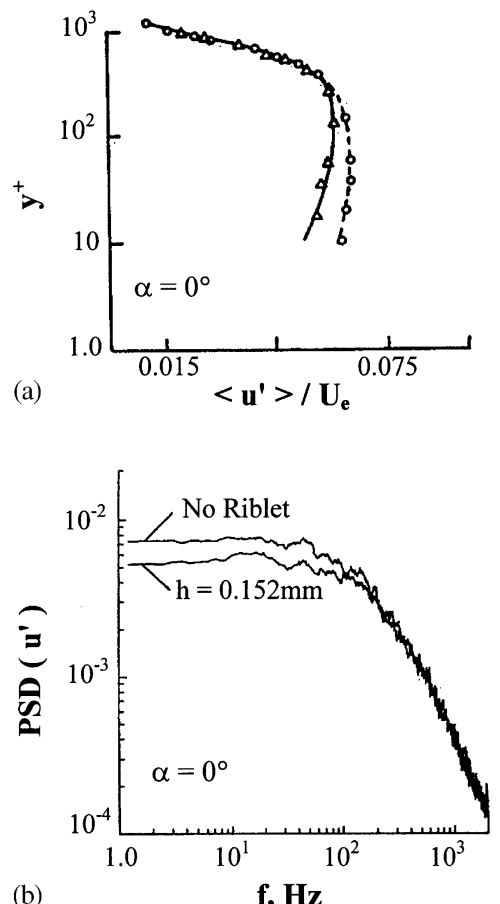

the boundary layer thickness $(\sim 0.4 \delta)$; the maximum reduction was about $10 \%$ and occurred at $y / \delta \sim 0.10$. Similar level of reduction in $\left\langle u^{\prime} v^{\prime}\right\rangle$ in the wall region due to riblets has been measured by Walsh [22] and Suzuki and Kasagi [18] in zero pressure gradient flows.

Quadrant analysis of $u^{\prime} v^{\prime}$ signals was performed [38] with a view to gain some understanding of the relative contribution of sweep and ejection events to the mean Reynolds stress under the influence of riblets at $\alpha=0^{\circ}$ and $6^{\circ}$; the measurements were made at selected $y$ locations in the boundary layer, the closest to the wall being at $y^{+} \sim 60$. The results of percentage stress (normalized by the mean turbulent shear stress) and the time or duration associated with the four quadrants at $\alpha=0^{\circ}$ and $6^{\circ}$ are presented in Figs. 15 and 16, respectively. At $\alpha=0^{\circ}(\beta=0.20)$, the duration of sweep and ejection events are even closer in the wall region under the influence of riblets; the contribution to the mean stress from sweep events seems slightly higher while a small reduction from ejection events is noticeable. The total stress from Q2 and Q4 motions is only weakly reduced by riblets.

With an increased adverse pressure gradient at $\alpha=6^{\circ}$ $(\beta \sim 1.06)$, the changes due to riblets both in percentage duration and contributions Q2 and Q4 events are more significant. The equalization of the duration associated with sweep and ejection motions are more spectacular
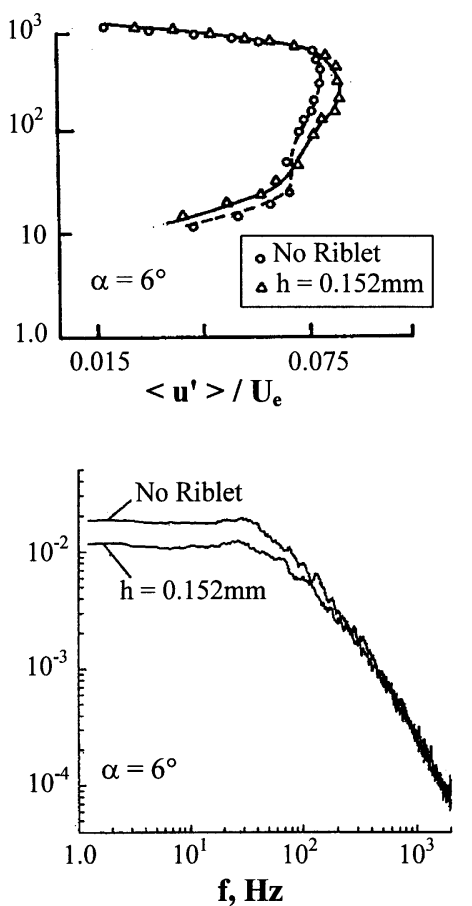

Fig. 13. Streamwise turbulent intensity profiles and power spectral density of $u^{\prime}$ on upper surface at $x / c=0.964$, NACA 0012 airfoil (taken from [32]). 
and extends to a greater distance from the wall $(y \sim 0.30 \delta)$. A reversal in the contribution from sweep and ejection events is clearly seen on the riblet surface; the contribution from sweep (Q4) events is enhanced by about $10 \%$, while a similar decrease is seen for the ejection (Q2) events for $y<3 \mathrm{~mm}$ (corresponding $y^{+}$ being around 250). The total stress from Q2 and Q4 (normalized by mean shear stress) remains about the same (about 120\%) as on the smooth wall. If the



Fig. 14. Turbulent shear stress profiles on upper surface at $\alpha=0^{\circ}$ and $6^{\circ}, x / c=0.964$, NACA 0012 airfoil.

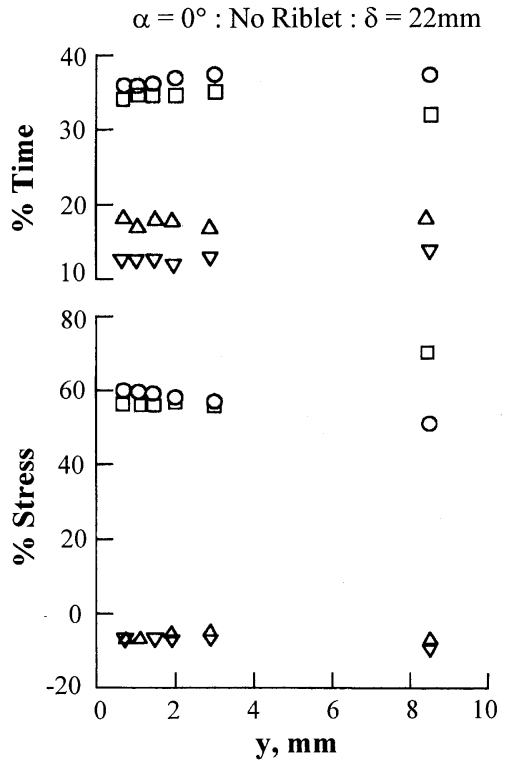

contributions from $\mathrm{Q} 2$ and $\mathrm{Q} 4$ events on the riblet surface are normalized by the mean turbulent shear stress values on the smooth wall (Fig. 14) in order to assess absolute changes, the following inference can be drawn: the contribution from sweep events will drop to (nearly) the same level as the unribbed case, while the contribution of ejection events will show a further decrease of about $5-10 \%$ (depending on the $y$ position). These results unambiguously suggest that, under high drag reduction conditions, the ejection events are appreciably inhibited by riblets and the reduction in the mean Reynolds shear stress is caused essentially by the lower contribution from ejection motion. The above observations also indicate that a certain modification of coherent motion (as discussed above) near the wall is a key factor influencing high skin friction drag reduction from riblets. The Q1 and Q3 events are only altered to a small extent by riblets.

In the light of the above observations, it is informative to take stock of results obtained from quadrant analysis on riblet surfaces in zero pressure gradient flows. Pulles et al. [43] found that fractional contribution to Reynolds stress from second quadrant (Q2) was reduced and fourth quadrant (Q4) increased at $y^{+}=38$; they suggested that ejection was weaker and sweep stronger on the grooved surface. The results from direct numerical simulation of Choi et al. [44] have revealed that riblets mitigate the positive Reynolds shear stress producing events (Q2 and Q4) in drag reducing configurations. The measurements of Benhalilou et al. [45] made on v-grooves $\left(s^{+}=34, h^{+}=17\right)$ have shown that, close to ridge plane, contributions to the Reynolds

$$
\alpha=0^{\circ}: \mathrm{h}=0.152 \mathrm{~mm}: \delta=22 \mathrm{~mm}
$$

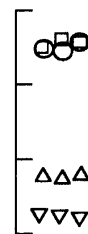

\section{$\bigcirc$ \\ 口 \\ $\nabla$}

$\Delta$



Fig. 15. Quadrant analysis of $u^{\prime} v^{\prime}$ signals on upper surface at $\alpha=0^{\circ}, x / c=0.964$, NACA 0012 airfoil. 

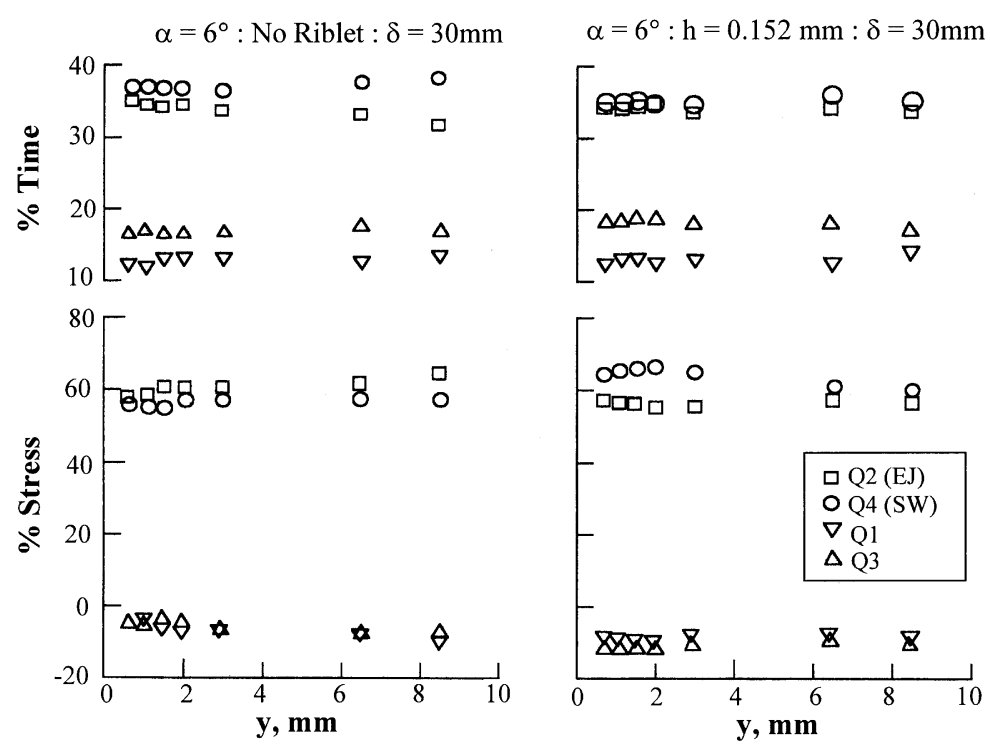

Fig. 16. Quadrant analysis of $u^{\prime} v^{\prime}$ signals on upper surface at $\alpha=6^{\circ}, x / c=0.964$, NACA 0012 airfoil.

stress from ejection and sweep events are larger and more frequent above the ridge (than over the smooth wall), while they are reduced above the valley.

In summary, available results from quadrant analysis indicate that riblets modify the ejection $(\mathrm{Q} 2)$ and sweep (Q4) events, while first- and third-quadrant events are nearly unchanged. These results imply that riblets do alter the organized motion that is associated with streamwise vortices near the wall; the changes seem more pronounced in adverse pressure gradients resulting in relatively higher skin friction drag reduction.

\subsection{Airfoils at transonic speeds}

It is useful to review the results under zero and mild pressure gradients at transonic speeds before addressing the performance of riblets on airfoils. Squire and Savill [26] were possibly the first to study the effectiveness of $3 \mathrm{M}$ riblets of varying sizes at a subsonic and transonic Mach number. They carried out tests in a wind tunnel at relatively high Reynolds numbers and Mach numbers of 0.88 and 0.50 . Skin friction reduction due to riblets was determined by plotting the ratio of the change in $\theta$ along the riblet surface to the corresponding change along the same length of smooth surface. Maximum skin friction drag reduction of about $5 \%$ was observed for the zero pressure gradient flow at both Mach numbers; the corresponding mean $h^{+}$range was 10-20. Riblet performance in adverse pressure gradients at $\beta^{+}=0.25$ was about the same as at $\beta=0$, while riblets were not effective at $\beta^{+}=0.50$.

On a cylindrical body at zero incidence Coustols and Schmitt [11] made drag measurements in the Mach number range of $0.30-0.815$ and the Reynolds number based on the riblet length $(=550 \mathrm{~mm})$ varied between $3.8-18.7 \times 10^{6} .3 \mathrm{M}$ riblets with $h=0.023,0.033,0.051$ and $0.076 \mathrm{~mm}$ were tested and they reported maximum skin friction drag reduction of $7-8 \%$ (Fig. 17) and the corresponding $\overline{h_{\mathrm{w}}^{+}}$range was $10-15\left(h_{\mathrm{w}}^{+}=\right.$riblet height scaled w.r.t. inner variables of the turbulent boundary layer at the wall; $\overline{h_{\mathrm{w}}^{+}}=$average of $h_{\mathrm{w}}^{+}$over riblet length). The above results of Squire and Savill [26] and Coustols and Schmitt [11] reveal that the effectiveness of riblets at transonic Mach numbers is about as good as at low speeds for zero and mild adverse pressure gradient conditions.

Coustols and Schmitt [11] presented results of riblet performance on a CAST 7 airfoil at zero incidence in the Mach number range of $0.65-0.76$. $3 \mathrm{M}$ riblets with $h=0.017,0.023,0.033$ and $0.051 \mathrm{~mm}$ were applied between $15 \%$ and $100 \%$ chord length and pitot surveys in the wake were utilized to measure the airfoil total drag. Total drag reduction of about $3.3 \%$ was observed for $h=0.023 \mathrm{~mm}$, while drag increases were found for riblets with $h=0.033$ and $0.051 \mathrm{~mm}$ (Fig. 18); the results for $h=0.017 \mathrm{~mm}$ were about the same as at $h=0.023 \mathrm{~mm}$ [11]. The above total drag reduction for $h=0.023 \mathrm{~mm}$ implied a viscous drag reduction of about $7.5-8 \%$ occurring in the range of $\overline{h_{\mathrm{w}}^{+}}$of $12-16\left(\overline{h_{\mathrm{w}}^{+}}\right.$is the mean value of integrated $h_{\mathrm{w}}^{+}$parameters evaluated along the manipulated surface on pressure and suction sides). These results showed the effectiveness of riblets on a transonic airfoil at zero incidence.

Transonic evaluation of drag reduction on a ADA-S1 supercritical airfoil over an incidence range of $-0.5^{\circ}$ to $+1.0^{\circ}$ was reported by Viswanath and Mukund [29]. 

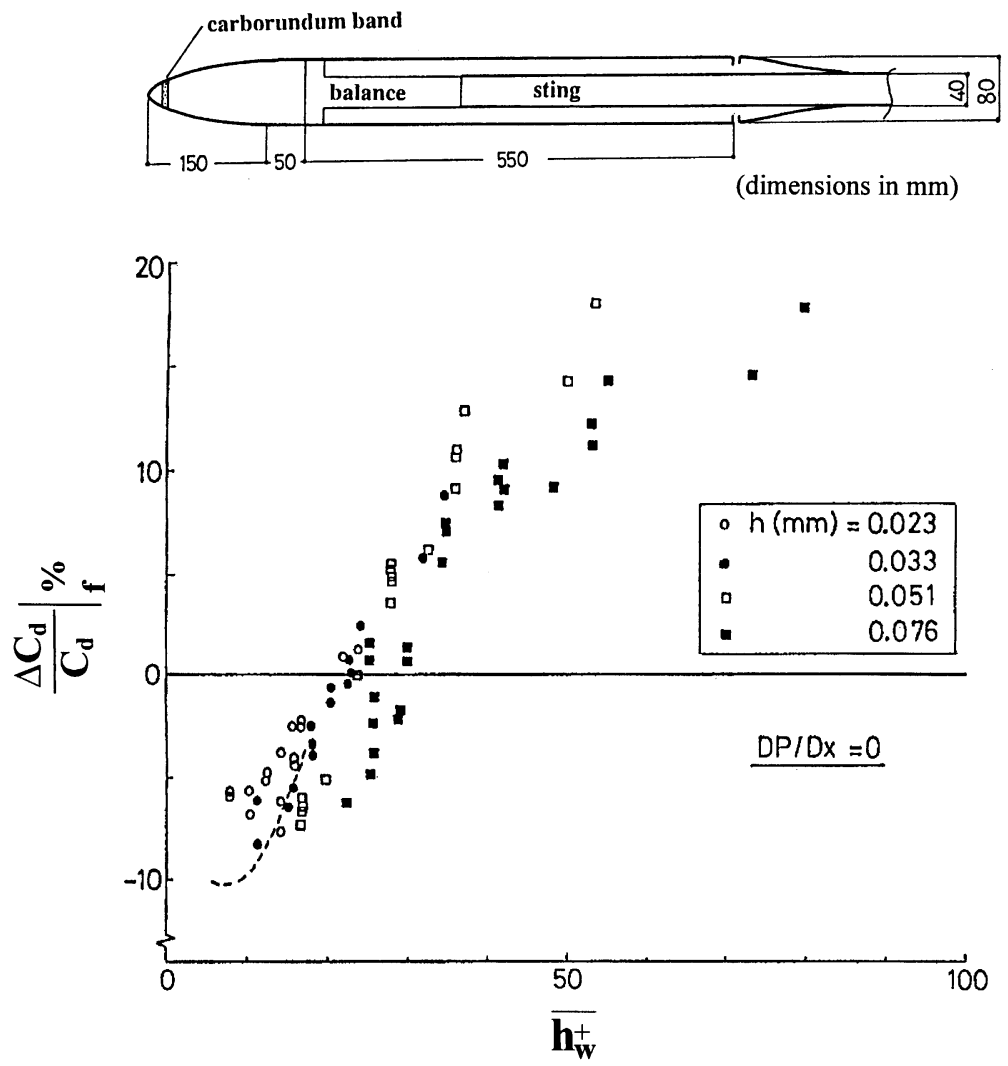

Fig. 17. Synthesis of drag data, ---- low-speed results (taken from [11]).



Fig. 18. Synthesis of drag measurements, CAST 7 aerofoil (taken from [11]).

Fig. 19 shows a sample of pressure distributions and the corresponding $h^{+}$variations for $h=0.018$ and $0.033 \mathrm{~mm}$; it would appear that riblets with $h=0.018 \mathrm{~mm}$ is a good choice for optimum drag reduction while a drag increase can be expected from $h=0.033 \mathrm{~mm}$. Measurements of total drag from wake survey method did confirm the above expectations [29]. Total drag measured for the optimized riblet 

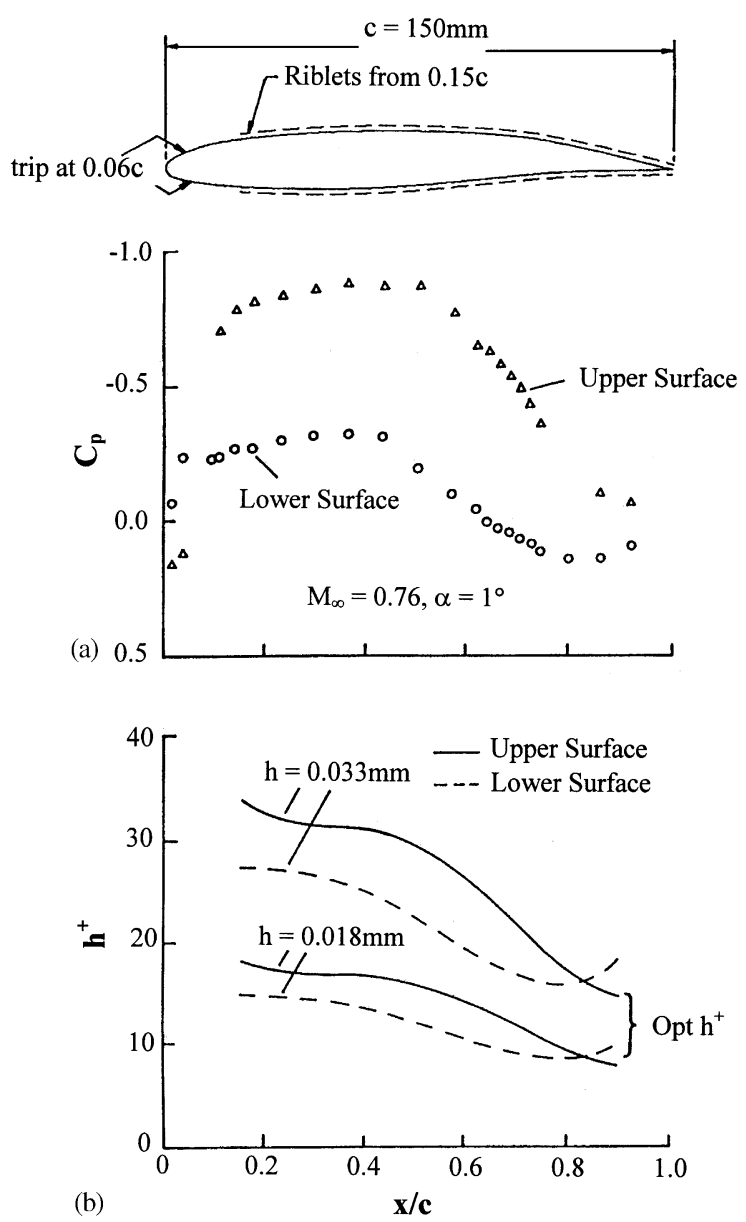

Fig. 19. Aerofoil characteristics: (a) static pressure distributions; (b) $h^{+}$variations, ADA-S1 airfoil.

$(h=0.018 \mathrm{~mm})$, as a percentage of the drag of the smooth airfoil, presented in Fig. 20 indicated a total drag reduction of $3-6 \%$; the corresponding skin friction drag reduction was estimated to be about $6-12 \%$. Notwithstanding a small degree of scatter in the data (Fig. 20), the trend of increasing drag reduction with $\alpha$, which implied increasing adverse pressure gradients on the airfoil upper surface was evident. The wake pitot profiles presented in Fig. 21, once again, indicated that a larger contribution to drag reduction resulted from the airfoil upper surface with increasing adverse pressure gradient. These results are consistent with those recorded on a CAST 7 airfoil and demonstrate that transonic effectiveness of optimized riblets can be about as good as those at low speeds over a range of incidence relevant in cruise applications. As we shall see in Section 5, flight measurements do provide additional support on the performance of riblets at transonic speeds.

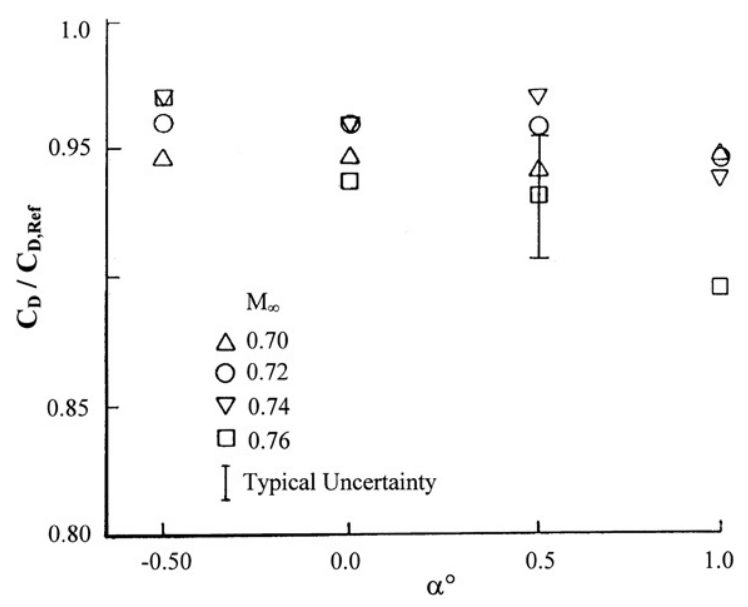

Fig. 20. Percentage total drag reduction with incidence; $h=0.018 \mathrm{~mm}$, ADA-S1 airfoil.



Fig. 21. Wake pitot profiles $\left(P_{\mathrm{o} y}\right.$ and $P_{\mathrm{o} \infty}$ are pitot pressure in wake and freestream), ADA-S1 airfoil.

\section{Swept wings}

Wing sweep results in three-dimensional boundary layers and very few studies exist examining the effectiveness of riblets in some detail. In addition to the 
presence of crossflow boundary layer, the riblet yaw angle effect could get pronounced with wing incidence. We shall discuss some of these aspects based on the available data.

Mclean et al. [12] reported estimates of (average) skin friction drag reduction from flight experiments on a $\mathrm{T}$ 33 jet trainer in the Mach number range of $0.35-0.70$; the wing had a sweep of about $9^{\circ}$ and $3 \mathrm{M}$ riblets with groove heights of 0.033 and $0.076 \mathrm{~mm}$ were applied only on the wing upper surface covering a streamwise distance of about $76 \%$ chord. Based on the estimates of momentum thickness (obtained from measured velocity profiles), they inferred viscous drag reduction upto $6 \%$ in the $h^{+}\left(=s^{+}\right)$range of $10-15$. We shall discuss these results in detail in Section 5.
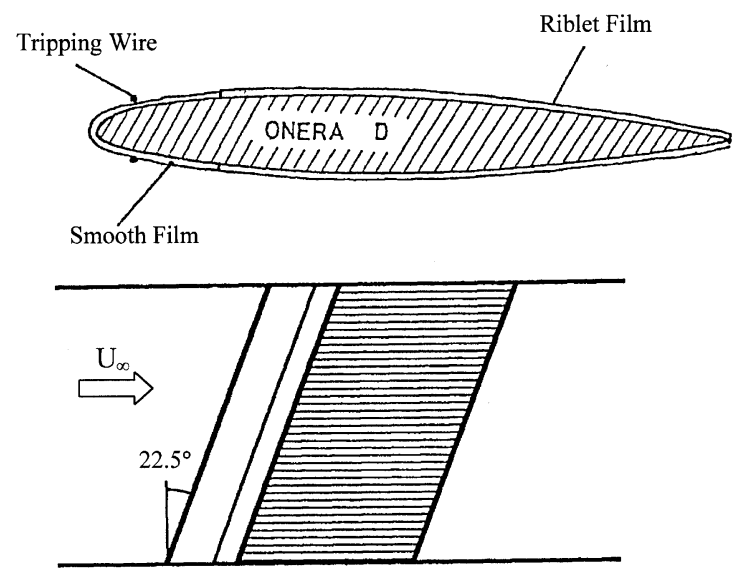

Fig. 22. ONERA D aerofoil covered with riblet film (taken from [46]).
The performance of riblets on an ONERA-D airfoil section, infinitely swept at $22.5^{\circ}$ (Fig. 22) and zero incidence was reported by Coustols [46]: $3 \mathrm{M}$ riblets of $h=0.152,0.076$ and $0.051 \mathrm{~mm}$ were used with grooves aligned parallel to the freestream direction and the manipulated area was about $85 \%$. Maximum total drag reduction of $3-3.5 \%$ was recorded (Fig. 23) for $\overline{h_{\mathrm{w}}^{+}}$ (average value of $h_{\mathrm{w}}^{+}$over the manipulated length on aerofoil upper surface) $<10$ in the chord Reynolds number range of $2.65-4.25 \times 10^{5}$ (the vertical lines in Fig. 23 refer to the experimental uncertainty); the corresponding skin friction drag reduction was estimated to be in the range of 5-6\%. Coustols recognized that the above level of drag reduction was some what lower than generally reported in 2D flows; his analysis showed that the riblet yaw angle $(\varphi)$ was quite small (less than $10^{\circ}$ over $90 \%$ chord) suggesting that the grooves must be effective.

\subsection{NAL studies on a swept wing with $G A W-2$ profile}

Sundaram et al. [36,37] presented detailed results of riblet performance on a swept wing (Fig. 24) at low speeds. The above experiments were made on a swept wing with a chord of $0.45 \mathrm{~m}$ and spanning the $1.5 \mathrm{~m} \times 1.5 \mathrm{~m}$ low-speed wind tunnel; the wing model having a $13.6 \%$ thick GAW-2 profile had a sweep of $25^{\circ}$ and the trailing edge (blunt with a thickness of $0.5 \%$ chord) was modified [36] to a sharp trailing edge to avoid flow complexity due to separation at the base. Riblet films were aligned parallel to the freestream and applied between $13 \%$ and $96 \%$ chord on both upper and lower surfaces. All the measurements were made at a chord Reynolds number of $0.75 \times 10^{6}$ covering an incidence range of $0-6^{\circ}$.

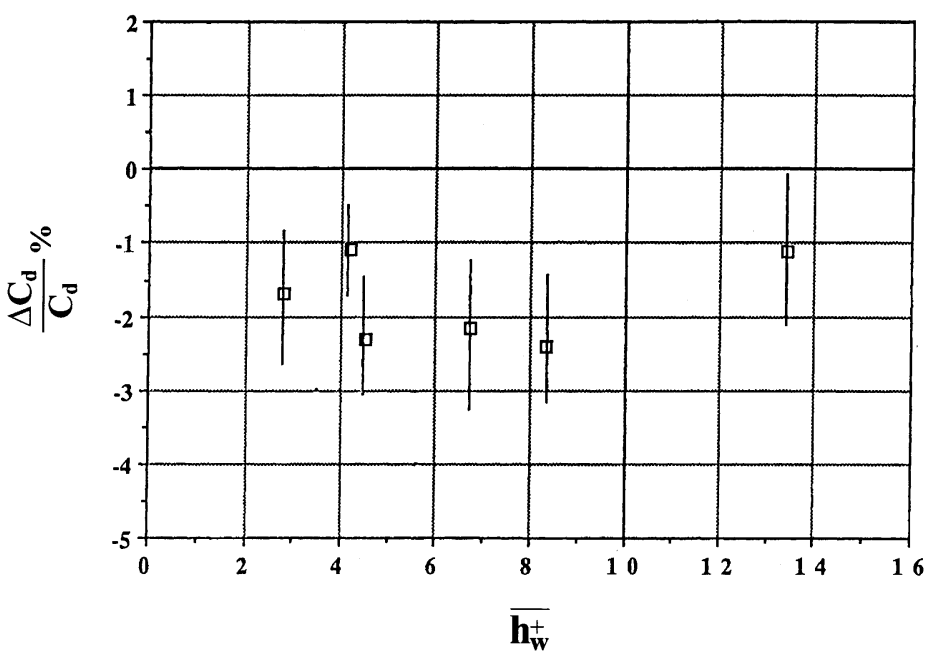

Fig. 23. Variations of total drag coefficient, ONERA D aerofoil (taken from [46]). 

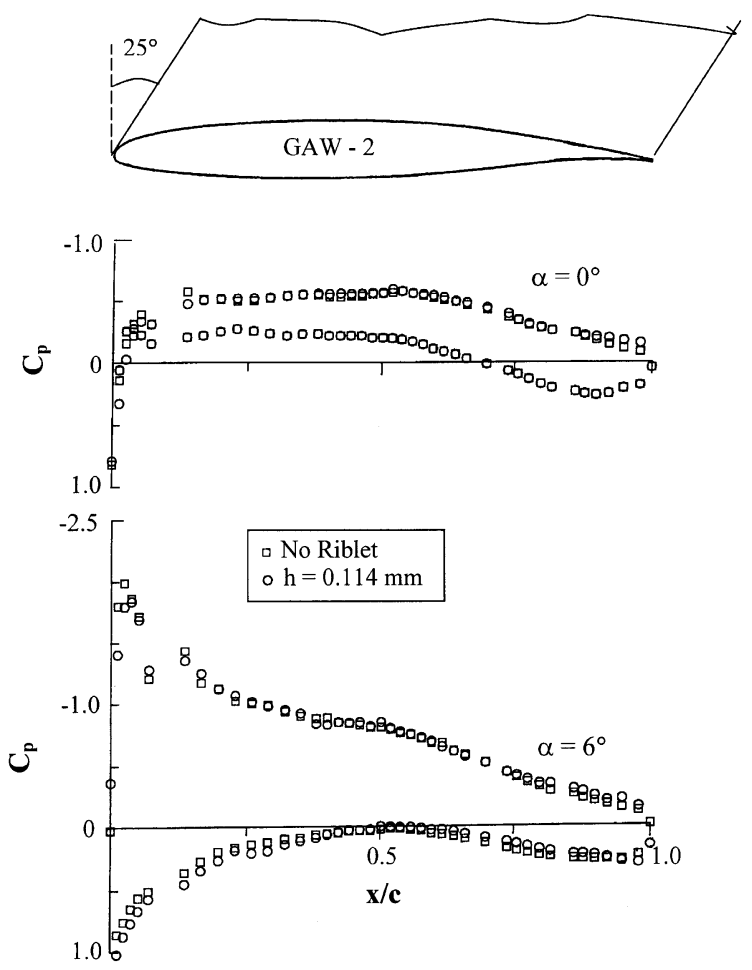

Fig. 24. Surface pressure distributions on swept wing, GAW-2 airfoil (taken from [37]).

\subsubsection{Selection of riblets}

Measured surface pressure distributions at $\alpha=0^{\circ}$ and $6^{\circ}$ are presented in Fig. 24 which shows again that the effect of riblets on surface pressure is small. Boundary layer calculations [41] were made using the measured streamwise $C_{\mathrm{p}}$ distributions on the wing upper surface. Fig. 25 shows computed variation of $h^{+}$on wing upper surface for three values of $h(0.152,0.114,0.076 \mathrm{~mm})$ at $\alpha=0^{\circ}$ and $6^{\circ}$. Riblet films with $h=0.114 \mathrm{~mm}$ was chosen as a good choice for all the measurements [36,37].

\subsubsection{Drag performance with incidence}

Fig. 26 shows results of percentage total drag and viscous drag reduction $\left(\Delta C_{\mathrm{f}} / C_{\mathrm{f}}\right)$ with incidence; the normalizing factor for total drag reduction at each $\alpha$ is the total drag of the smooth airfoil without riblets. Estimate of $\beta$ calculated using an average pressure gradient (as defined in Section 3.3.2) at each $\alpha$ is also included in Fig. 26. Total drag reduction of $6 \%$ and skin friction drag reduction of $8 \%$ observed at $\alpha=0^{\circ}$ are in good agreement with the drag reduction that has been observed on 2D airfoils and in zero pressure gradient flows. With an increase in $\alpha$, both total and viscous drag reduction decreased progressively, which is in sharp contrast with the observation made on $2 \mathrm{D}$ airfoils (Fig. 6).



Fig. 25. Variation of $h^{+}$on upper surface, GAW-2 airfoil (taken from [37]).


Fig. 26. Variations of drag reduction and Clauser parameter with incidence on swept wing, GAW-2 airfoil.

\subsubsection{Assessment of riblet yaw angle effects}

On a swept wing, two factors that may influence the performance of riblets are the crossflow boundary layer and the associated yaw angle $(\varphi)$ between surface streamlines and groove direction. Sundaram et al. 



$$
\alpha=0^{\circ}
$$

$$
\alpha=6^{\circ}
$$

Fig. 27. Flow features on upper surface of swept wing, GAW-2 airfoil (taken from [37]).

$[36,37]$ carried out extensive surface flow visualisation studies and samples of features of surface streamlines on the wing upper surface at $\alpha=0^{\circ}$ and $6^{\circ}$ shown in Fig. 27; the photographs clearly indicate noticeable deviation of surface streamlines from freestream (or groove direction) as incidence is increased. Quantitative estimates of $\varphi$ inferred from flow visualization studies $[36,37]$ are plotted against $x / c$ at different $\alpha$ (Fig. 28). At $\alpha=0^{\circ}$ and $2^{\circ}, \varphi<10^{\circ}$ over a large fraction of the chord but increases to about $15^{\circ}$ towards the trailing edge; at $\alpha=4^{\circ}$ and $6^{\circ}, \varphi$ increases rapidly beyond $x / c=0.60$ and has a value of about $27^{\circ}$ at $\alpha=6^{\circ}$ near the trailing edge. On the wing lower surface, although $\varphi \leqslant 10^{\circ}$, a large part of the wing chord (beyond $x / c=0.30$ ) is affected by $\varphi$ effects including a reversal of surface flow direction beyond $x / c=0.75$.

On a swept wing, $\varphi$ effects are associated with crossflow boundary layer as well as streamwise pressure gradients and it is a complex task to separate out their effects on riblet drag reduction. In this context, available information on 2D and axisymmetric configurations


Fig. 28. Streamwise variation of riblet yaw angle on swept wing, GAW-2 airfoil (taken from [37]).

examining $\varphi$ effects alone, e.g. Refs. $[8,11,12,46]$, is of some help. It is now generally known that both the magnitude of drag reduction and the value of $h^{+}$upto which drag reduction is retained is sensitive to $\varphi$; a useful guideline that emerges is that drag reduction may be limited to $\varphi \leqslant 15-20^{\circ}$, although the level of drag reduction may be considerably lower than the optimum (corresponding to $\varphi \sim 0^{\circ}$ ). The (max) skin friction drag reduction of about $8 \%$ measured at $\alpha=0^{\circ}$ is infact consistent with other measurements (Coustols [46], Mclean et al. [12]) and observed values of $\varphi$ which are much less than $15^{\circ}$ (Fig. 28). It has been argued by Sundaram et al. [37] that a major factor responsible for the degraded performance of riblets at higher $\alpha\left(4^{\circ}\right.$ and $6^{\circ}$ ) is the larger streamwise extent and larger values of $\varphi$ in the adverse pressure gradient region on the wing upper surface, which contributes appreciably to drag reduction (like on airfoils).

It is to be recognized that even a broad understanding of riblet effectiveness in a three-dimensional boundary layer does not exist, and there is need to isolate different effects. It would be very informative to investigate the effectiveness of riblets with sweep alone in the absence of any streamwise pressure gradient (e.g. swept flat plate at zero incidence) in future experiments.

\subsubsection{Boundary layer properties ahead of the trailing edge}

Sundaram et al. [37] presented the measurements of streamwise mean velocity, $\left\langle u^{\prime}\right\rangle$ and $\left\langle u^{\prime} v^{\prime}\right\rangle$ profiles 
made at $x / c=0.960$ on both upper and lower surfaces of the swept wing at zero incidence, which are displayed in Figs. 29 and 30. As in 2D airfoil flows, riblets result in higher velocities in the boundary layer on the wing upper surface (Fig. 29) while the effects are much weaker on the lower surface; these results indicate again that the wing upper (or suction) surface is the major contributor to the observed drag reduction. The results of $\left\langle u^{\prime}\right\rangle$ show a $(\max )$ reduction of about $8 \%$ due to riblets on the wing upper surface with negligible change on the

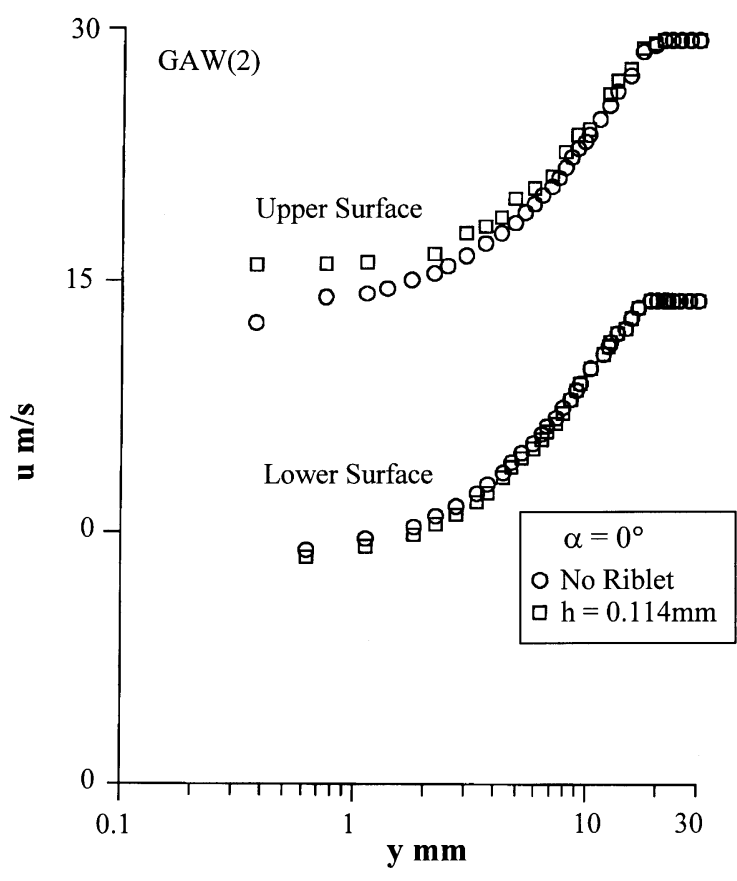

Fig. 29. Mean velocity profiles on swept wing at $x / c=0.96$ and $\alpha=0^{\circ}$, GAW-2 airfoil (taken from [37]). lower surface (Fig. 30). Reduction in turbulent shear stress values due to riblets (about 6-7\%) in the wall region of the upper surface can be observed whereas no such reduction is seen on the wing lower surface (Fig. 30).

A useful guideline that emerges is that, as long as $\varphi$ values are relatively small $\left(<10^{\circ}\right)$, moderate wing sweep may not adversely affect the performance of riblets. The results of $\left\langle u^{\prime}\right\rangle$ and $\left\langle u^{\prime} v^{\prime}\right\rangle$ profiles under the influence of riblets (discussed above) show features qualitatively similar to those on 2D airfoil flows at low speeds.

While certain broad conclusions on the effect of moderate wing sweep on riblet performance emerge from low-speed results, there is a definite need to investigate in detail transonic effects (including aspects of shock wave-boundary layer interaction) on a transport aircraft wing from the point of view of applications.

\section{Flight investigations}

The performance of $3 \mathrm{M}$ riblets has been assessed at relatively high Reynolds numbers in flight tests as well. McLean et al. [12] at Boeing reported results of skin friction drag reduction with riblet films glued over a partspan on the upper surface of one wing of a T-33 jet trainer (Fig. 31); the wing sweep was about $9^{\circ}$. The tests were made in the flight Mach number range of $0.35-0.70$ and the Reynolds number per $\mathrm{ft}$ varied from 1.45 to $4.43 \times 10^{6}$; the lift coefficient varied from 0.08 to 0.43 . $3 \mathrm{M}$ riblet films with a height of 0.0013 in $(0.033 \mathrm{~mm})$ and 0.003 in $(0.076 \mathrm{~mm})$ were used and their coverage on the test surface extended from $7 \%$ to $83 \%$ local chord of the wing. Boundary layer pitot rake measurements (located at $83 \%$ chord), with and without riblets, were utilized to determine the change in momentum thickness and therefore the reduction in the mean skin friction drag over the test surface.
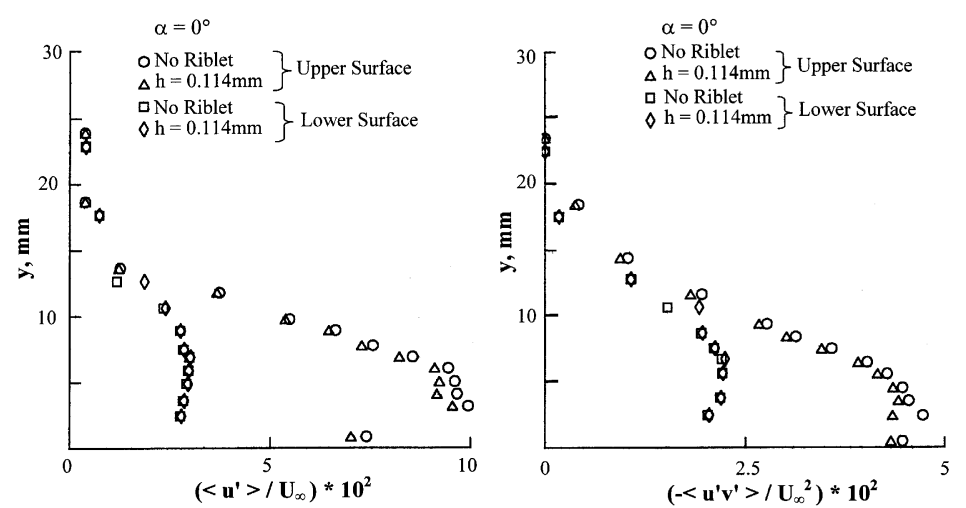

Fig. 30. Streamwise turbulent intensity and Reynolds shear stress profiles on swept wing at $x / c=0.96, \alpha=0^{\circ}, \mathrm{GAW}-2$ airfoil (taken from [37]). 


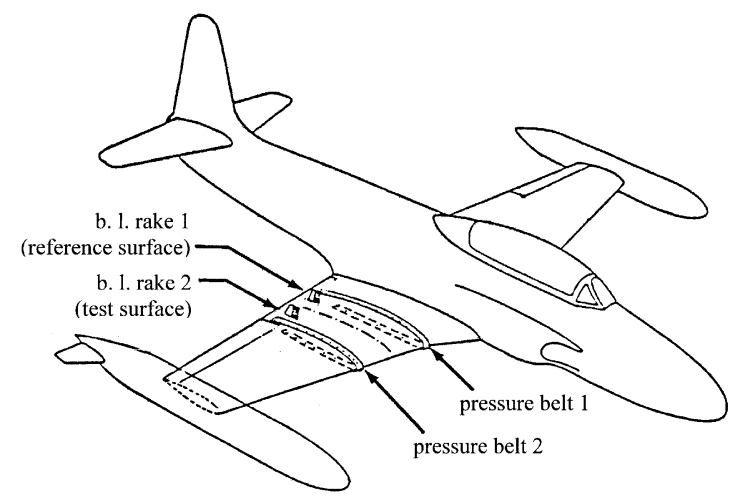

Fig. 31. Test surface and instrumentation on T-33 airplane (taken from [12]).

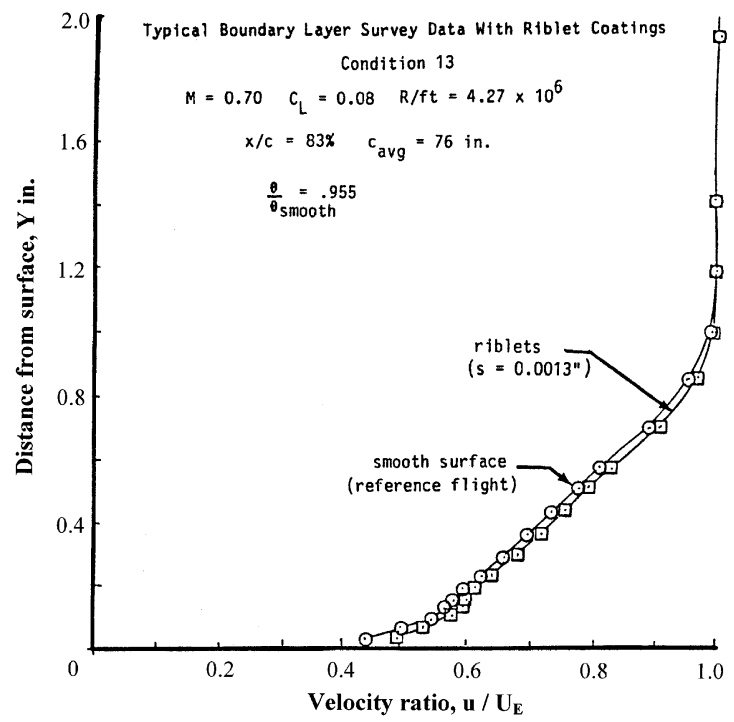

Fig. 32. Typical boundary layer rake data behind riblet and reference surfaces (taken from [12]).

Fig. 32 shows the alteration of the mean velocity profile due to riblets (measured at $x / c=0.83$ ) at a flight Mach number of 0.70 . The mean velocity profile in the presence of riblets is slightly fuller away from the wall with a lower velocity gradient, $\partial u / \partial y$, at the surface; this feature of riblets is typical and has been noticed in wind tunnel measurements as well, e.g. Ref. [19,32]. Typical results from two flights showed maximum skin friction drag reduction of about $6-7 \%$ in the $s^{+}$(averaged over $x / c$ between 0.07 and 0.83 ) range between $10-15$ (Fig. 33); the performance of riblets with $h=0.0013$ and 0.003 in was very similar.

McLean et al. made a flight assessment of two important aspects, namely, influence of adverse pressure gradients and of yaw angle $(\varphi)$ on the effectiveness of riblets. In one of the flights, a smooth plastic film



Fig. 33. Measured $\theta$ ratios compared with NASA $C_{\mathrm{f}}$ ratios (taken from [12]).

replaced the riblets aft of $x / c=0.50$, which was approximately the location where the adverse pressure gradients began on the T-33 wing under most flight conditions [12]. The measured skin friction drag reduction with riblet height of 0.0013 in were appreciably lower (about $2-3 \%$ ) than those observed with riblets extending all the way upto $x / c=0.83$ (Fig. 33), providing explicit evidence that riblets are quite effective in adverse pressure gradients. In a different flight, the riblets were oriented at $15^{\circ}$ to the flight direction and the results showed considerably lower drag reduction (about 3\%), suggesting a relatively stronger degradation of riblet effectiveness due to yaw angle under flight conditions.

Flight results reported by Walsh et al. [13] at NASA Langely provide further support concerning effectiveness of riblets at high Reynolds numbers. The tests were made with $3 \mathrm{M}$ riblet films glued to the fuselage of a modified Learjet Model 28/29 twin-engine business jet in the Mach number range of $0.30-0.70$; the corresponding Reynolds number range was $1.0-2.75 \times 10^{6} / \mathrm{ft}$. Riblets with $h=0.0013$ in $(0.033 \mathrm{~mm})$ and 0.003 in $(0.076 \mathrm{~mm})$ were tested (same geometry as those used by McLean et al.).

The performance of riblets was assessed at two locations on the aircraft fuselage (Fig. 34), which provided nearly zero pressure gradient conditions and flow angularity. Riblet films were glued to the test panel (of length $5.83 \mathrm{ft}$ and width $1 \mathrm{ft}$ located $6.2 \mathrm{ft}$ aft of aircraft nose) and boundary layer pitot rake measurements along with 2D momentum integral balance were employed to infer mean skin friction reduction over the test surface. Local skin friction measurements were 




Fig. 34. Streamlines calculated using the VSAERO panel method (taken from [13]).

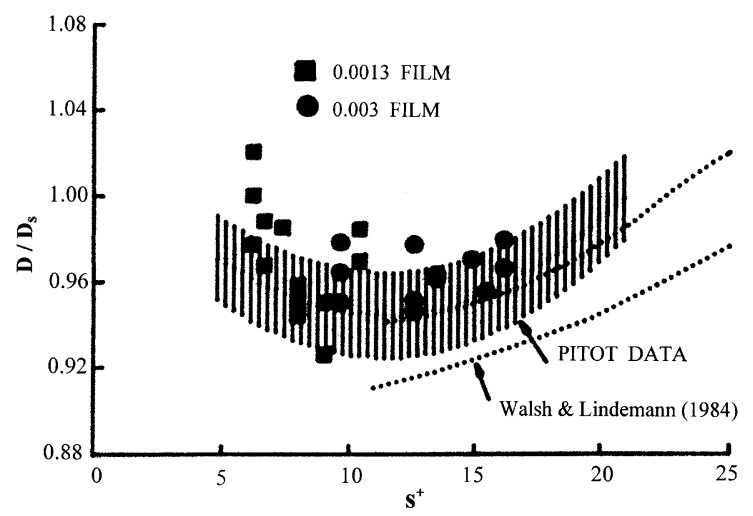

Fig. 35. Drag balance and pitot rake data compared. $D$ and $D_{\mathrm{s}}$ are drag of test surface and smooth reference surface (taken from [13]).

made using two, accurate flush mounted drag balances (located $17 \mathrm{ft}$ from the nose of the aircraft); considerable care was taken to enhance the accuracy of these measurements. The drag data obtained by both balance and pitot rakes (Fig. 35) showed fair agreement and the maximum skin friction drag reduction of about $6 \%$ observed in the $s^{+}\left(=h^{+}\right)$range of $10-15$, is in good conformity with the flight results obtained by McLean et al. (Fig. 33). Further analysis [13] using a panel method revealed that small degree of flow angularity existed in the zone where the balances were located (Fig. 34) and therefore may have caused some reduction in the riblet effectiveness.

The likely effects of perforations in the riblet films (which is being considered as a possible method of allowing for the escape of cabin pressurization air through rivet holes) on drag reduction have been assessed both by McLean et al. [12] and Walsh et al. [13]. Riblets with 0.01 in perforations with centre spacings of 0.25 in were found to give nearly the same level of drag reduction as the non-perforated films.

In summary, flight evaluation of riblet effectiveness at high Reynolds numbers and Mach numbers in the range of $0.30-0.70$ has given strong support to the wind tunnel correlations of drag reduction. Maximum skin friction drag reduction of about $6 \%$ has been observed both in fuselage tests (under nearly zero pressure gradient conditions) and wing tests including adverse pressure gradients, and the optimum $s^{+}\left(=h^{+}\right)$range being 10 15 ; these results are in very good agreement with large body data obtained in wind tunnel studies at relatively lower Reynolds numbers. The flight results of McLean et al. have provided additional support regarding the effectiveness of riblets in adverse pressure gradients and an assessment of likely degradation in riblet performance arising from riblet yaw angle effects.

\section{Wing-body and aircraft configurations}

As we have discussed, the available data on airfoils at subsonic and transonic speeds and swept wing at low speeds indicate that skin friction drag reduction in the range of 5-8\% are achievable for the optimized riblets at zero or low $\alpha$. On cylindrical bodies, measurements of Coustols and Schmitt [11] at relatively high Reynolds numbers have shown $(\max )$ skin friction reduction of about $7-8 \%$ for the optimized riblets at zero incidence (friction drag force on this model contributed to about $96 \%$ of total drag) and over a range of Mach numbers between 0.30 and 0.81 . On a wing-body or transport aircraft configuration, the effective viscous drag reduction will primarily depend on two factors: area covered by riblets and whether the riblet geometry is optimized for the wing and fuselage flows appropriately. Further, the performance of riblets may be severely affected in zones of large three-dimensionality (e.g. around wingbody junction, wing tip and rear fuselage regions).

Coustols and Schmitt [11] studied the effectiveness of $3 \mathrm{M}$ riblets on a 1:11 scale of an Airbus A-320 wingbody model in the Mach number range of $0.30-0.82$ and incidence range of $-2^{\circ}$ to $3^{\circ}$; the (max) Reynolds number based on the fuselage length of $3.416 \mathrm{~m}$ was about $40 \times 10^{6}$. Riblet films with $h=0.023 \mathrm{~mm}$ were used with grooves aligned to the external freestream direction and the area covered by the grooves was about $66 \%$ on the wing-body configuration; the above groove depth was optimized for the fuselage flow at $M_{\infty}=0.70$. Accurate drag measurements were made using an internal six-component balance and net total drag reduction of $1.6 \%$ was measured over a range of $C_{\mathrm{L}}$ of $0.1-0.60$ at a Mach number of 0.70 ; the corresponding skin friction drag reduction was estimated to be about $4.85 \%$. They suggested that the above value of drag reduction was not the highest since the groove size had not been optimized for wings and further, the wetted area covered by riblets was only about $66 \%$.

Van Der Hoven and Bechert [30] reported drag measurements using a six-component strain gauge balance on a 1:4.2 model of DORNIER Do-228 commuter aircraft in the DNW wind tunnel in the freestream velocity range of $40-90 \mathrm{~m} / \mathrm{s}$; the corresponding Reynolds number based on the wing (centre section) 
chord was $1.37 \times 10^{6}$ and $3.09 \times 10^{6}$, respectively. Riblet films with $h=0.076 \mathrm{~mm}$ were chosen which was a compromise considering optimum $h^{+}$for the fuselage and wings and the grooves were aligned parallel to the freestream. Balance measurements (with tripping devices on the fuselage and wings) showed drag reduction in the range of $1-6 \%$. The authors however indicated that drag reduction of $6 \%$ was rather unrealistic because of certain inaccuracies in the balance measurements; a total drag reduction of $2-3 \%$ was considered more reliable.

Recently limited tests at transonic speeds have been performed in our laboratory on a wing-body model whose sketch is included in Fig. 2. $3 \mathrm{M}$ riblets with $h=0.018 \mathrm{~mm}$ was applied on the wing upper surface and $h=0.023 \mathrm{~mm}$ was used on the wing lower surface and on the cylindrical fuselage. Riblets were aligned parallel the freestream and their coverage on the wing-body was about $90 \%$. Six-component balance measurements were made over an incidence range of $-1^{\circ}$ to $1.5^{\circ}$. Circular end plates were attached at wing tips primarily to minimize the contribution of induced drag in the drag measurements. Preliminary examination of the data at a Mach number of 0.76 suggests a total drag reduction of about $3-4 \%$; detailed analysis of the results is in progress.

Flight evaluation of riblet performance on an Airbus A320 aircraft has been reported by Szodruch [14]. About $70 \%$ of the aircraft surface was covered with $3 \mathrm{M}$ riblets (Fig. 36) and total drag reduction was assessed based on fuel burn saving in flight tests. These tests revealed a

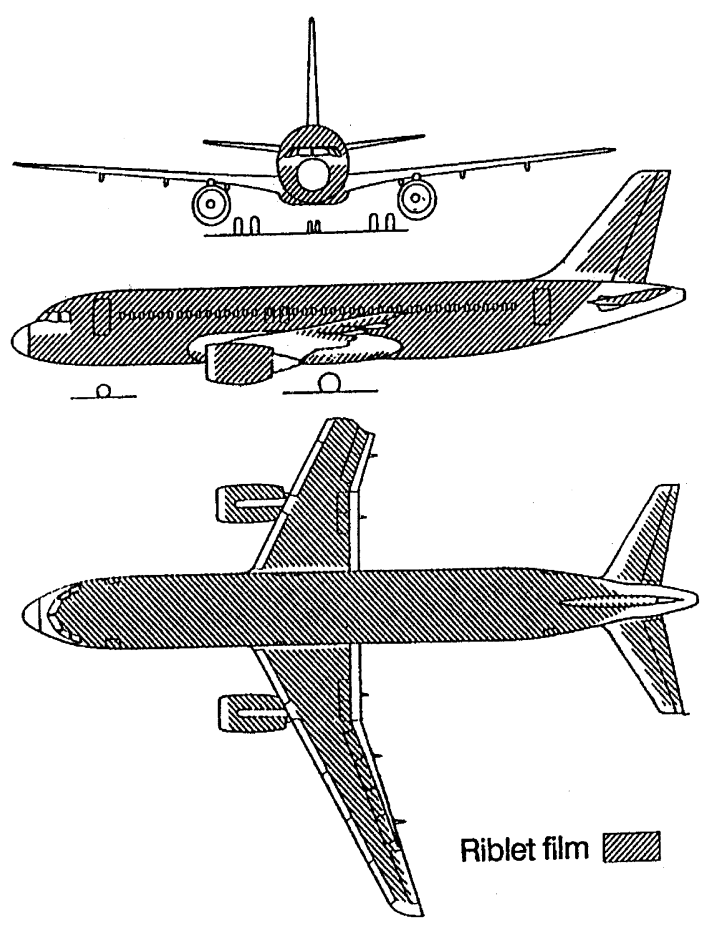

Fig. 36. A-320 no.1 covered with riblet film (taken from [14]). total drag reduction of a little less than $2 \%$ in the Mach number range of $0.77-0.79$, in conformity with their predictions [14]. There results are extremely significant since they reflect benefits in actual flight applications.

\section{Riblets at supersonic speeds}

It is reasonable to expect that effectiveness of riblets will prevail in the supersonic regime since the microgrooves will be well immersed in the low-speed/subsonic velocity field atleast upto moderate supersonic Mach numbers. The potential of using riblets at supersonic speeds has been discussed by Bushnell [6]. Limited wind tunnel investigations including flight test results are available in supersonic flow.

Robinson [47] noticed a reduction in the streamwise turbulence intensity near the wall and a thickening of the viscous sublayer due to $3 \mathrm{M}$ riblets at a Mach number of 2.97. Gaudet [48] reported drag reduction results due to $3 \mathrm{M}$ riblets at a freestream Mach number of 1.25 and in the range of Reynolds number of $2.4-11 \times 10^{6} / \mathrm{m}$. Experiments were made on the turbulent boundary layer developing along the wall of the wind tunnel using riblets of $h=0.051 \mathrm{~mm}$. Maximum local skin friction reduction upto $7 \%$ was measured using a drag balance.

Coustols and Cousteix [49] assessed the performance of $3 \mathrm{M}$ riblets on a cone-cylinder body at zero incidence at freestream Mach numbers of 1.60, 2.0 and 2.50; the test Reynolds number range was 4.9 to $22.3 \times 10^{6} / \mathrm{m}$. Riblet films with height of $0.033,0.051$ and $0.076 \mathrm{~mm}$ were investigated and accurate drag measurements were made using a one-component balance. Typical drag results for $h=0.051 \mathrm{~mm}$ are shown in Fig. 37. At $M_{\infty}=$ 2.0 and 2.5 , net drag reduction was observed for all three values of $h$; at $M_{\infty}=1.60$, some drag increase was recorded for unit Reynolds numbers $>15 \times 10^{6}$. These results implied maximum viscous drag reduction upto about $6 \%$ which occurred around a value of $\overline{h_{\mathrm{w}}^{+}}$(average value of $h_{\mathrm{w}}^{+}$along the manipulated length) of 10. It may, therefore, be noted that the supersonic wind tunnel test results of skin friction drag reduction in nominally zero pressure gradient conditions are in good agreement with the available data at low and transonic speeds.

The flight test results reported by Zuniga et al. [50] provide additional support regarding the effectiveness of $3 \mathrm{M}$ riblets at supersonic speeds. Riblets with height of 0.003 in $(0.076 \mathrm{~mm})$ and 0.0013 in $(0.033 \mathrm{~mm})$ were fixed on a F-104G flight test fixture (FTF) (Fig. 38), and they were tested in a design Reynolds number range selected to provide maximum skin friction drag reduction. The FTF experimental setup is presented in Fig. 39 and riblets were applied to the right side test surface only. Boundary layer rakes were employed to measure the velocity profiles for the smooth and riblet surfaces and the average wall skin friction over the test surface was 

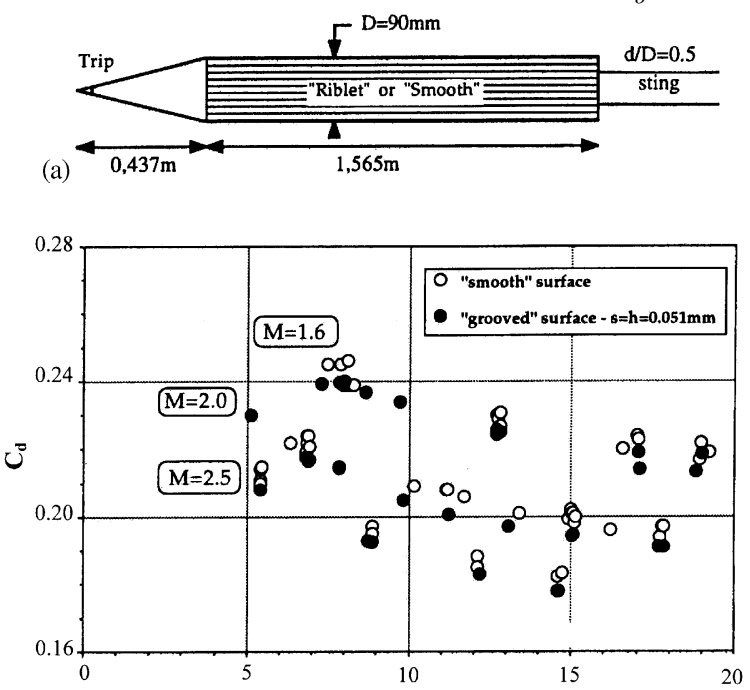

(b)

Re 1m (million)

Fig. 37. Variation of viscous drag coefficient of the model (taken from [49]).

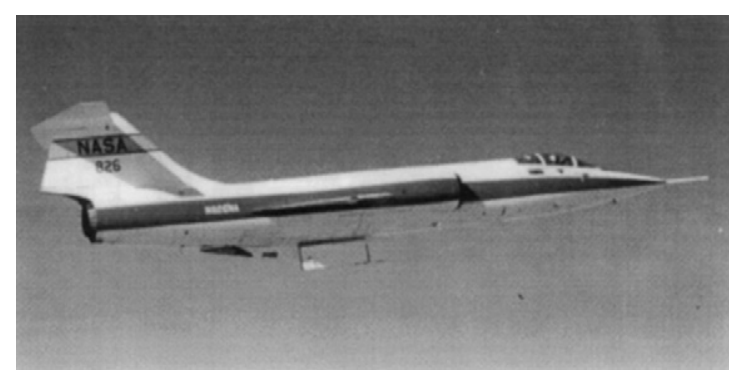

Fig. 38. Flight test fixture mounted on F-104G aircraft (taken from [50]).

determined using the 2D momentum integral equation. The chordwise pressure distributions measured on the FTF revealed a region of strong adverse pressure gradients in the Mach number range of 1.20-1.40; these effects were relatively milder at Mach 1.5 and 1.60. In essence, the test results on the FTF reflect performance of riblets under conditions, which include effects of adverse pressure gradients as well.

Figs. 40 and 41 show results of average skin friction corresponding to smooth and riblet surfaces for the riblet height of 0.076 and $0.033 \mathrm{~mm}$, respectively. The test conditions including Mach number and Reynolds number range and observed (average) skin friction drag reduction are summarized below:

Flight test conditions and results [50]

\begin{tabular}{llll}
\hline$h(\mathrm{~mm})$ & $M_{\infty}$ & $R e / \mathrm{ft}$ & $\Delta C_{\mathrm{f}} / C_{\mathrm{f}}(\%)$ \\
\hline 0.076 & $1.2-1.6$ & $2-3.4 \times 10^{6}$ & $4-8$ \\
0.033 & $1.2-1.4$ & $3.6-6 \times 10^{6}$ & $4-15$ \\
\hline
\end{tabular}

The above flight results, while providing strong support to the wind tunnel evaluation of riblet effectiveness at supersonic speeds, show a trend of increased viscous drag reduction with Reynolds number at Mach 1.2 and 1.4 (for $h=0.076 \mathrm{~mm}$ ) and at Mach 1.2 and 1.3 (for $h=0.033 \mathrm{~mm}$ ); the authors [50] suggested that such trends are difficult to substantiate because of the scatter and limited data. It was shown [50] that drag reduction for $h=0.076 \mathrm{~mm}$ (as an example) occurred in $h^{+}$range of 9-15 and therefore in good agreement with the low-speed correlation of viscous drag reduction.

\section{Effect of riblets on lift characteristics}

This aspect is very relevant from an application point of view. Van Der Hoven and Bechert [30] presented lift characteristics on a 1:4.2 model of Do-228 commuter aircraft model at low speeds which is reproduced in Fig. 42; the results show clear evidence of a small increase in lift curve slope (about $1 \%$ according to the authors) over the entire $\alpha$ range of $-5^{\circ}$ to $+20^{\circ}$ investigated. This slope increase obviously results from reduced boundary layer displacement thickness distributions caused by riblets; essentially riblets lead to a lower viscous decambering effect on the wing. Such a beneficial effect may be expected to be more pronounced on a transonic wing, where the viscous effects play a major role. Fig. 43 presents sectional lift characteristics on the GAW-2 swept wing [38] upto $\alpha=6^{\circ}$ at low speeds and the results are in broad agreement with the observations on Do-228 model: the lift curve slope is increased by about $1 \%$. The results of Do-228 also showed that $C_{\mathrm{L}}(\max )$ and the corresponding stall angle were unaffected by riblets; further there was no evidence of premature flow separation or hysterisis [30].

\section{Base drag reduction on airfoils}

The effectiveness of riblets for viscous drag reduction on airfoils and wings have been discussed so far. There have been very few attempts exploring the use of riblets in separated flows, either from the point of view of drag reduction or separation control. In the context of base flow problems, it is generally known [51-53] that the base pressure depends on the development of the free shear layer, which in turn is affected by the initial boundary layer conditions just ahead of the base. It is well established that riblets reduce both the displacement and momentum thicknesses in a boundary layer, e.g. Ref. [8]. Some of the earlier studies have revealed that the near-wall flow is affected by riblets, which includes a reduction in streamwise turbulent intensity 


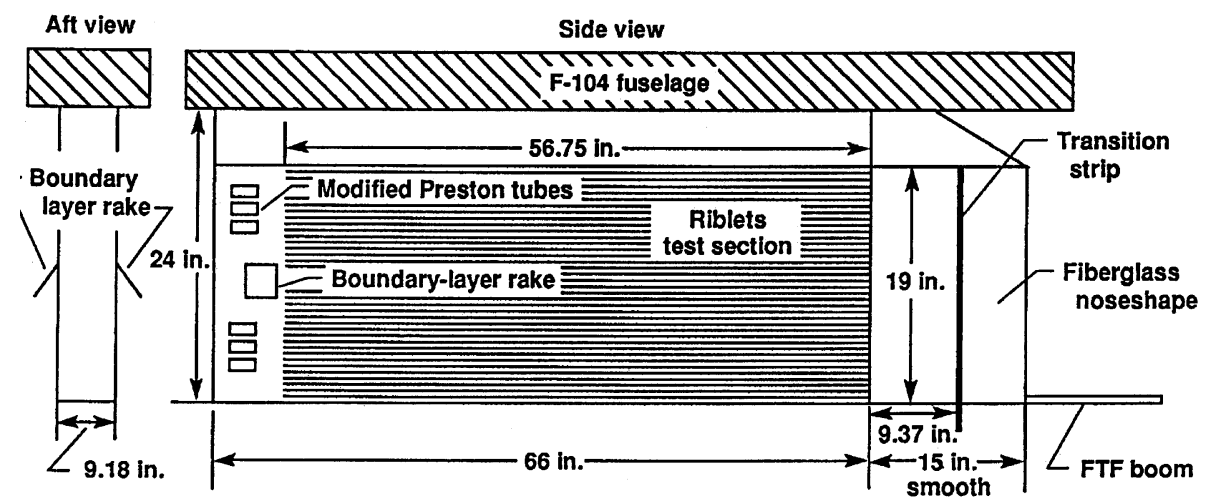

Note: figure not drawn to scale

920002

(a) Right side.

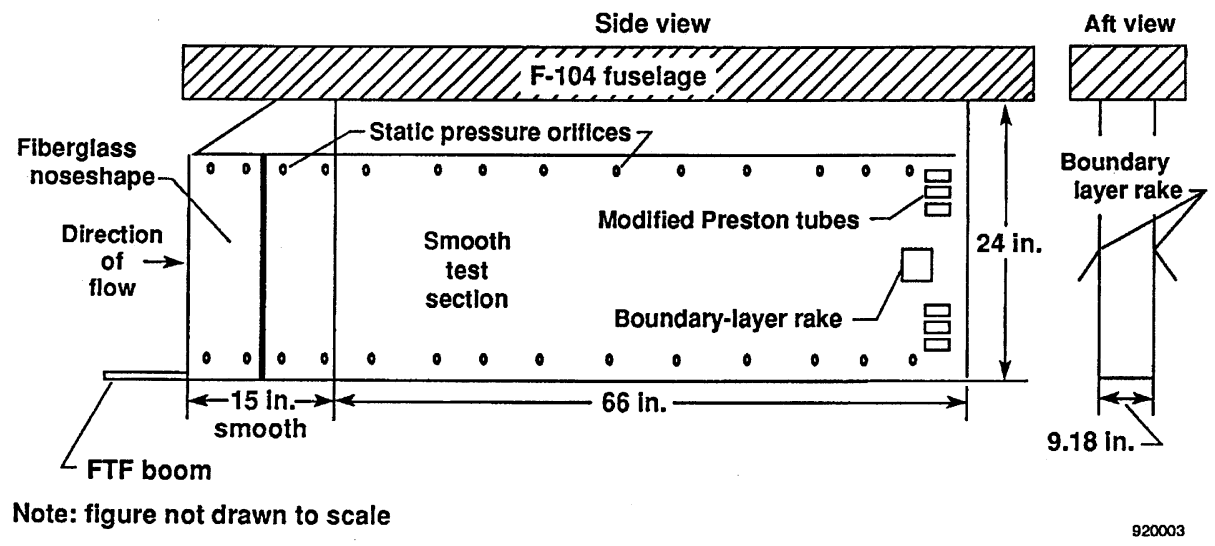

(b) Left side.

Fig. 39. Flight test fixture experiment setup (taken from [50]).

(as much as 10-20\%) and Reynolds shear stress (about 10-15\%). It was therefore conjectured [54] that the combination of lower mean velocity gradient $(\partial u / \partial y)$ close to the wall and reduced levels of $\left\langle u^{\prime}\right\rangle$ and $\left\langle u^{\prime} v^{\prime}\right\rangle$ in the wall region of the approaching boundary layer (ahead of the blunt base) may favourably affect the shear layer development because the mixing zone is relatively short (comparable to trailing-edge thickness) on an airfoil; reduced mixing in the free shear layer could lead to lower velocity along the dividing streamline resulting in higher base pressure.

With this in background, Channaraju and Viswanath [54] made an assessment of riblets for base drag reduction on a GAW(2) airfoil (See Fig. 2) which has a trailing-edge thickness of $0.5 \%$ chord; on a model scale with a chord of $600 \mathrm{~mm}$, the trailing-edge thickness was $3 \mathrm{~mm}$. Riblet films with a height of 0.076 and $0.152 \mathrm{~mm}$ were applied between $0.12 c$ and $0.96 c$ on the airfoil top and bottom surfaces. Streamwise variations of $h^{+}$calculated for the measured pressure distributions on the airfoil upper surface showed that riblets with $h=0.076$ and $0.152 \mathrm{~mm}$ would be optimum at $\alpha=0^{\circ}$ and $6^{\circ}$ (Fig. 44), respectively, considering viscous drag reduction. They made measurements of base pressure, model surface pressures and total drag using wake survey.

The base pressure coefficient (Fig. 45) for the baseline airfoil (without riblets) was positive at all $\alpha$ indicating a base thrust. Interestingly, the base pressure showed an increase with $h$ in the $\alpha$ range considered and it was as high as $50 \%$ at $\alpha=6^{\circ}$ for $h=0.152 \mathrm{~mm}$. Although the increase in base thrust was large, the base drag reduction, however, as a fraction of total drag of the airfoil was only about $0.7 \%$ since the base drag component of the baseline airfoil was itself small. Even this low level of drag reduction is of engineering value since it is an added benefit due to riblets on a blunt trailing-edge airfoil. The increase in base pressure due to riblets was attributed to be a direct consequence of two 


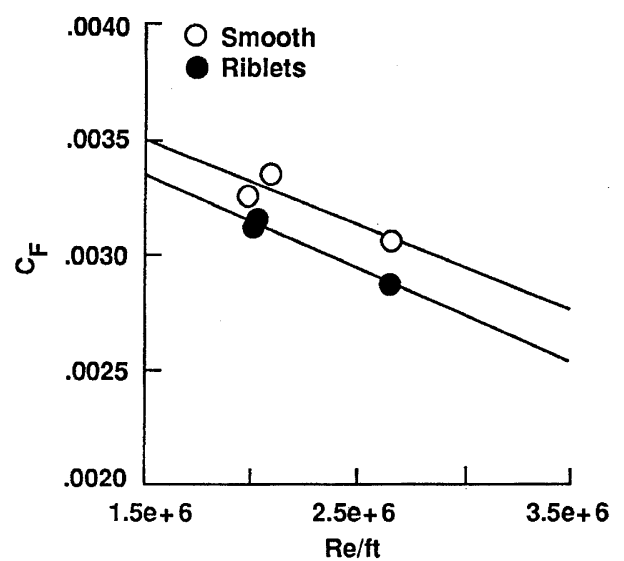

(a) Mach 1.2.



(c) Mach 1.5.

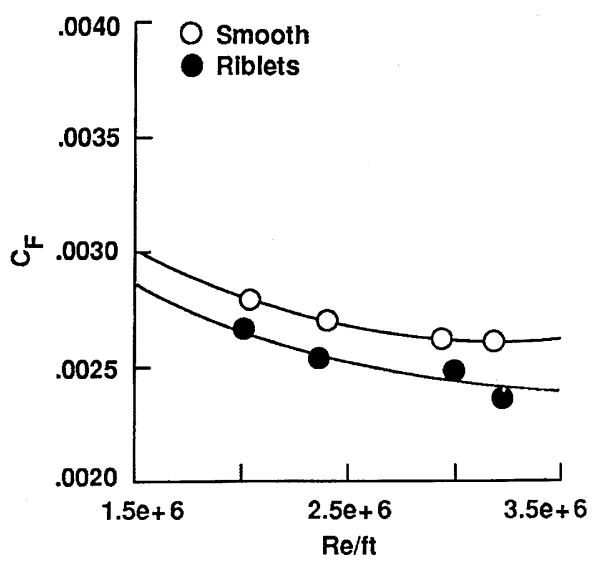

(b) Mach 1.4.

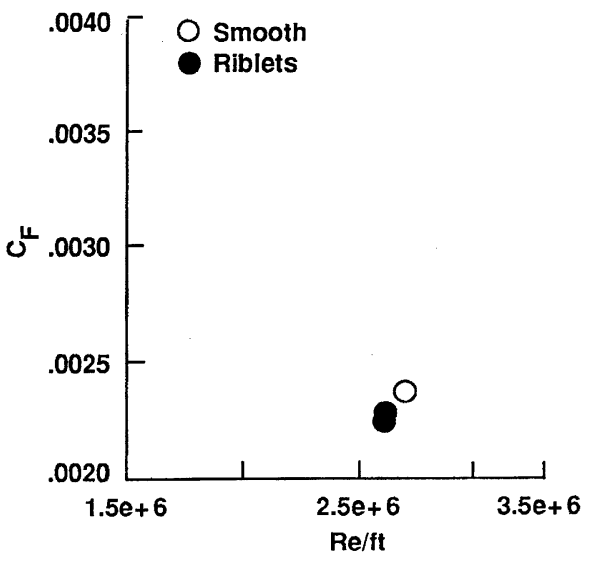

(d) Mach 1.6.

Fig. 40. Average skin-friction coefficient for 0.0030 in riblets compared with unit Reynolds number for Mach $1.2-1.6$ (taken from [50]).

factors: a lower effective base height of the airfoil (including the boundary layer displacement thickness) and altered shear layer development characteristics as discussed above. It would be of significant engineering interest to assess base drag reduction from riblets on a supercritical airfoil with a blunt trailing edge at transonic speeds.

\section{Concluding remarks}

Research investigating the performance of riblets for viscous drag reduction has received considerable attention during the last two decades. Riblet films with adhesive backing manufactured by $3 \mathrm{M}$ company, USA have been utilized very widely in riblet research both in wind tunnels and in flight tests. In this review, we have addressed primarily the effectiveness of $3 \mathrm{M}$ riblets for turbulent skin friction drag reduction on airfoils, wings and wing-body combinations in different speed regimes; these applications bring in issues of riblet performance in pressure gradients and in the presence of threedimensionality. Based on the available experimental data, certain broad conclusions are drawn, which are informative both from the point of view of design applications as well as flow features associated with riblets.

The data base generated in wind tunnels and flight experiments at high Reynolds number firmly establish the effectiveness of riblets from low speed to moderate supersonic Mach numbers. Taking into account (typical) uncertainties in the measured data, the performance of riblets may be judged to be about the same across the Mach number range investigated. With optimized riblets, skin friction drag reduction in the range of $5-8 \%$ are achievable on $2 \mathrm{D}$ airfoils at low incidence and 


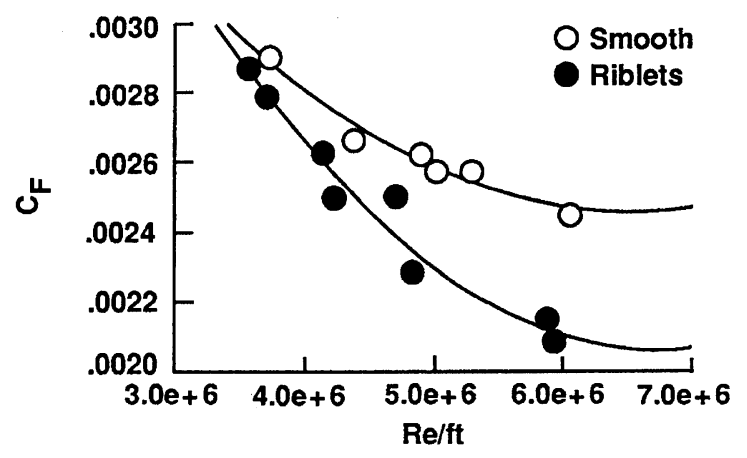

(a) Mach 1.2.



(b) Mach 1.3.

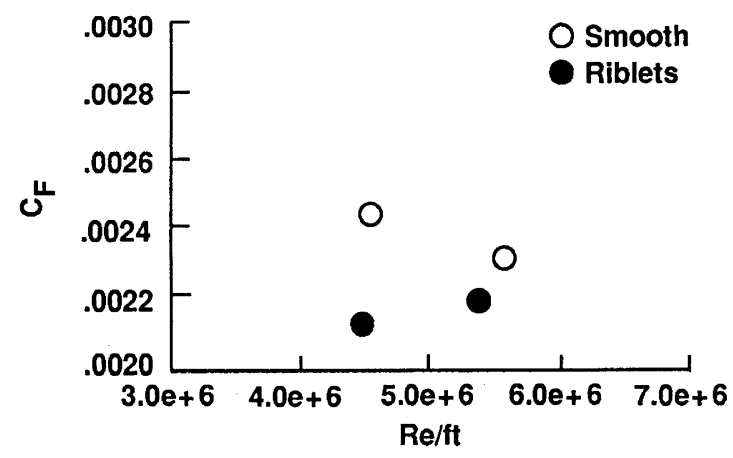

(c) Mach 1.4.

Fig. 41. Average skin-friction coefficient for 0.0013 in riblets compared with unit Reynolds number for Mach 1.2-1.4 (taken from [50]).

in flows with mild adverse pressure gradients; there is broad consistency amongst different measurements that the above level of drag reduction is achieved for $h^{+}$in the range of $8-15$, which is in very good agreement with the large body of data available on zero pressure gradient flows. The correlation of viscous drag reduction vs $h^{+}$, well established for zero pressure gradient boundary layer flows, can be a useful guide for choosing the optimum riblet size in pressure gradients. Detailed



Fig. 42. Lift characteristics on Do-228 model (taken from [30]).

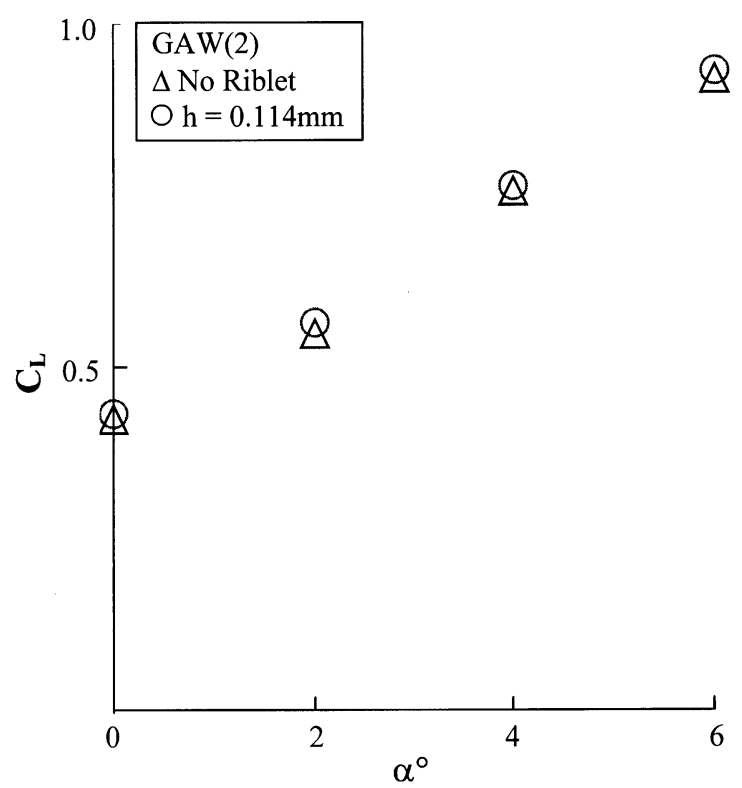

Fig. 43. Sectional lift characteristics on swept wing, GAW-2 airfoil.

low-speed experiments have shown a trend of increasing viscous drag reduction with airfoil incidence initially, in contrast with some of the early results in the literature; the increased drag reduction is contributed by the airfoil 

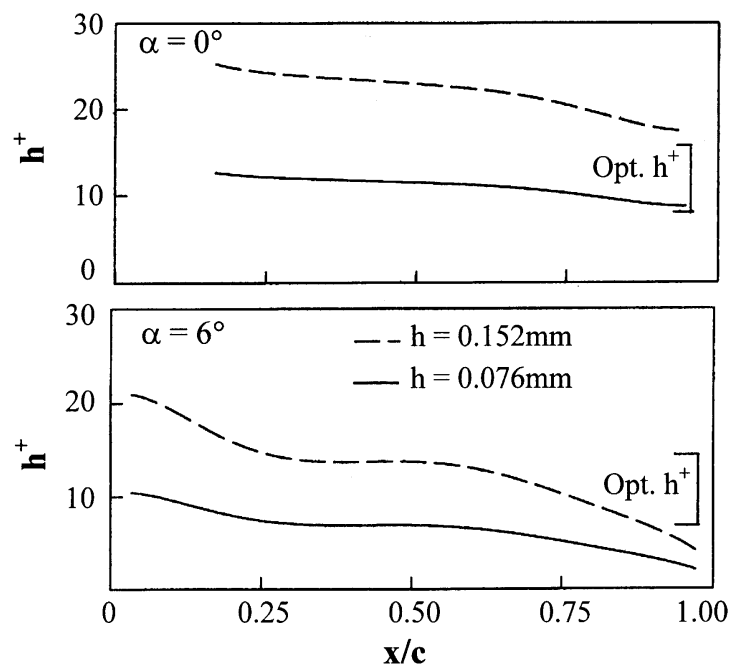

Fig. 44. Streamwise variations of $h^{+}$on upper surface, GAW-2 airfoil (taken from [54]).



Fig. 45. Variation of base pressure coefficient with incidence (taken from [54]).

suction surface, suggesting increased effectiveness of riblets in adverse pressure gradients; similar observations at low speeds have been made in riblet studies on a flat plate with imposed adverse pressure gradients.

With regard to altered flow features arising from riblets, the following major observations are made. (i) As in zero pressure gradients flows, riblets in adverse pressure gradients $(\beta \leqslant 2.20)$ do show an increased intercept in the mean velocity profile plotted in log-law coordinates, suggesting thickening of the sublayer (although there may be some exceptions). (ii) In adverse pressure gradients on airfoils, the influence of riblets is not confined to the near-wall region but could extend well into the boundary layer to a height of as much as
$20-30 \%$ of the boundary layer thickness. (iii) Turbulent intensity $\left\langle u^{\prime}\right\rangle$ and Reynolds shear stress profiles $\left\langle u^{\prime} v^{\prime}\right\rangle$ in the wall region do show a visible reduction due to riblets in adverse pressure gradient as well. (iv) Under high drag reduction conditions in adverse pressure gradients, quadrant analysis of $u^{\prime} v^{\prime}$ signals indicate that ejection events near the wall are appreciably inhibited, thereby affecting turbulent energy production. Further research investigating the mechanics of riblets in adverse pressure gradients may be very fruitful since it may provide a "sensitive flow configuration" involving large viscous drag reduction and flow alteration to a sufficient degree, making it more amenable to accurate measurements and interpretation. It would also be very informative to assess in some detail typical effects of riblets on shockwave-turbulent boundary layer interaction on airfoils at transonic speeds.

Detailed experiments on moderately swept wings relevant to transport aircraft applications are limited and the available results at low speeds (with riblet grooves aligned to the freestream direction) indicate that viscous drag reduction in the range of 5-8\% is likely for optimized riblets at zero incidence. With increasing $\alpha$, the riblet yaw angle $(\varphi)$ effects may become large $\left(\varphi>15^{\circ}\right)$ and degrade the performance of riblets appreciably. In addition to the crossflow boundary layer, we may in general expect that both the magnitude of $\varphi$ and its streamwise gradient will be relevant factors affecting riblet performance in a 3D boundary layer. The available results strongly suggest that aligning the riblet grooves along the local surface streamline direction on a swept wing (e.g. corresponding to cruise conditions) would be necessary in order to realize maximum benefit in applications. There is a definite need for detailed studies on a moderate swept wing (relevant to transport aircraft) at transonic speeds investigating the mean properties of the boundary layer which would enhance our broad understanding of riblet performance both due to three-dimensionality as well as other aspects like shock-boundary layer interaction; such attempts would result in improved guidelines for the practical application of riblets.

Limited wind tunnel data available on wing-body or aircraft model configuration suggest that a total drag reduction of $2-3 \%$ can be expected which is very encouraging. In addition to as large a coverage of riblets as possible, it is essential to optimize riblets for the wing and fuselage components (corresponding to cruise conditions) in order to realize maximum drag reduction. Total drag reduction, a little less than $2 \%$, has been reported by Szodruch [14] based on fuel consumption measurements in flight tests in the Mach number range of $0.77-0.79$ on an Airbus A-320 aircraft with a riblet coverage of about $70 \%$; these results were found to be extremely consistent with the expectation from wind tunnel results. 
While the drag reduction capability has been demonstrated beyond doubt, there are certain important issues concerning utilization of $3 \mathrm{M}$ riblets in transport aircraft applications. These include cost of riblet films, time and cost of installation and removal of riblet films, performance degradation of riblets due to aging and other operational aspects: excellent discussion of many of the above issues are contained in the papers by Hirschel et al. [3] and Lynch and Klinge [55]. Application of riblets to high speed trains and trucks/buses may prove to be very beneficial; for these applications, riblet geometry can be optimized to provide higher viscous drag reduction $(8-10 \%)$ and the grooves could possibly be formed as an integral part of the manufacturing process of the skin so that the economic gain can be substantial.

Suggestions have been made concerning the use of 3D riblets/humplets and limited studies exist examining the performance of certain $3 \mathrm{D}$ riblet geometries including (idealized) biological surfaces for viscous drag reduction, e.g. [16,56-59]; the drag reduction benefits vary considerably and $(\max )$ skin friction drag reduction in the range of $8-9 \%$ have been measured at low speeds[16]. A major question is whether $3 \mathrm{D}$ riblets can offer viscous drag reduction much higher than 2D grooves (e.g. $3 \mathrm{M}$ riblets). The choice of $3 \mathrm{D}$ riblet geometry can indeed be very wide and systematic work in the future is needed to assess the drag reduction potential of $3 \mathrm{D}$ riblets in general and their optimization. It remains to be seen if any passive flow control technique or device for skin friction drag reduction will prove to be so successful that it reaches the final goal of in-service aircraft applications.

In this review, we have focussed attention on experimental results concerning riblet performance on airfoils, wing and wing-body configurations. There have been several attempts to calculate the flow-field and assess drag reduction due to riblets, e.g. [44,60-62]. The article by Pollard [62] may be seen for a review of calculation methods.

\section{Acknowledgements}

The author is extremely grateful to his colleagues who, over the years, have contributed to many aspects of riblet research at NAL: special thanks are due to Drs. Sundaram S, Subashchandar N, Channa Raju, Rudra Kumar S, and Mr. Mukund R. Valuable suggestions were made by Prof. Roddam Narasimha on an early version of this paper to whom the author expresses grateful thanks. Some aspects of the research reported here were funded by the Aeronautical Development Agency, Bangalore.

\section{References}

[1] Thomas ASW. Aircraft drag reduction technology-a summary. Aircraft drag prediction and reduction. AGARD-R-723, 1985, Paper No. 1.

[2] Bushnell DB. Turbulent drag reduction for external flows. Aircraft drag prediction and reduction. AGARD-R-723, 1985, Paper No. 5.

[3] Hirschel EH, Thiede P, Monnoyer F. Turbulence management-application aspects. Fluid dynamics of threedimensional turbulent shear flows and transition. AGARD-CP-438, Paper No. 23, 1988.

[4] Bushnell DB. Supersonic aircraft drag reduction. AIAA Paper 90-1596, 1990.

[5] Bushnell DB. Aircraft drag reduction. Special course on skin friction drag reduction. AGARD-R-786, 1992, Paper No. 3.

[6] Bushnell DB. Viscous drag reduction in aeronautics. Proceedings of the 19th Congress International Council Aeronautical Science. Paper 94-0.1, Anaheim, CA, 1994.

[7] Robert JP. Drag reduction: an industrial challenge. Special Course on Skin Friction Drag Reduction. AGARD-R786, 1992, Paper No. 2.

[8] Walsh MJ. Riblets. In: Bushnell DB, Hefner JN, editors. Progress in astronautics and aeronautics. Washington, DC: AIAA, 1990, p. 203-61.

[9] Coustols E, Savill AM. Turbulent skin-friction drag reduction by active and passive means. Special course on skin friction drag reduction. AGARD-R-786, 1992. Paper No. 8.

[10] Coustols E. Riblets: main known and unknown features. In: Choi KS, Prasad KK, Truong TV, editors. Emerging techniques in drag reduction. Mechanical Engineering Publications, UK, 1996. p. 3-43.

[11] Coustols E, Schmitt V. Synthesis of experimental riblet studies in transonic conditions. In: Coustols E, editor. Turbulence control by passive means. Netherlands: Kluver Academic, 1990. p. 123-40.

[12] McLean JD, George-Falvy DN, Sullivan PP. Flight-test of turbulent skin friction reduction by riblets. Proceedings of International Conference on Turbulent Drag Reduction by Passive Means, Section 16. London: Royal Aeronautical Society, 1987. p. 1-17.

[13] Walsh MJ, Sellers WL. Riblet drag reduction at flight conditions. AIAA Paper 88-2554, 1988.

[14] Szodruch J. Viscous drag reduction on transport aircraft. AIAA Paper 91-0685, 1991.

[15] Walsh MJ, Lindemann AM. Optimization and application of riblets for turbulent drag reduction. AIAA Paper 840347, 1984.

[16] Bruse M, Bechert DW, Th van der Hoeven JG, Hage W, Hoppe G. Experiments with conventional and with novel adjustable drag - reducing surfaces. In: So RMC, Speziale CG, Launder BE, editors. Near wall turbulent flows. Amsterdam: Elsevier Science Publishers, 1993. p. 719-38.

[17] Schwarz-van Manen AD, Thijssen JHH, Nieuwvett C, Prasad KK, Nieuwstadt FTM. The bursting process over drag reducing grooved surfaces. In: Gyr A, editor. Proceedings of the IUTAM Symposium on Structure of Turbulence and Drag Redction. Berlin: Springer, 1990. p. 561-8. 
[18] Suzuki Y, Kasagi N. Turbulent drag reduction mechanism above a riblet surface. AIAA J 1994;32(9):1781-90.

[19] Choi KS. Near-wall structures of a turbulent boundary layer with riblets. J Fluid Mech 1989;208:417-58.

[20] Choi KS. Turbulence structure revisited: results and implications from riblets research. In: So RMC, Speziale CG, Launder BE, editors. Near wall turbulent flows. Amsterdam: Elsevier Science Publishers, 1993. p. 699-707.

[21] Bechert DW, Bartenwerfer M. The viscous flows on surfaces with longitudinal ribs. J Fluid Mech 1989; 206:105-30.

[22] Walsh MJ. Drag characteristics of v-groove and transverse curvature riblets. In: Hough GR, editor. Progress in astronautics and aeronautics. New York: AIAA, 1980. p. 168-84.

[23] Vukoslavcevic P, Wallace JM, Balint JL. Viscous drag reduction using streamwise aligned grooves. AIAA J 1992;30(4):1119-22.

[24] Park SR, Wallace JM. Flow-field alteration and viscous drag reduction by riblets in a turbulent boundary layer. AIAA Paper 93-3256, 1993.

[25] Pulvin Ph, Truong TV. Riblets in internal flows with adverse pressure gradients. In: Gyr A, editor. Proceedings of the IUTAM Symposium on Structure of Turbulence and Drag Reduction. Berlin: Springer, 1990. p. 569-76.

[26] Squire LC, Savill AM. Drag measurements on planar riblet surfaces at high subsonic speeds. Appl Sci Res 1989;46:229-43.

[27] Nieuwstadt FTM, Wolthers W, Leijdens H, Krishna Prasad K, Schwarz-van Manen A. The reduction of skin friction by riblets under the influence of an adverse pressure gradient. Expt Fluids 1993;15:17-26.

[28] Coustols E, Cousteix J. Experimental investigation of turbulent boundary layers manipulated with internal devices: riblets. In: Gyr A, editor. Proceedings of the IUTAM Symposium on Structure of Turbulence and Drag Reduction. Berlin: Springer, 1990. p. 577-84.

[29] Viswanath PR, Mukund R. Turbulent drag reduction using riblets on a supercritical airfoil at transonic speeds. AIAA J 1995;33(5):945-7.

[30] Van Der Hoven JG, Bechert DW. Experiments with a 1:4.2 model of a commuter aircraft with riblets in a large wind tunnel. In: Choi KS, editor. Recent developments in turbulence management. Dordrecht, Netherlands: Kluwer Academic Publishers, 1991. p. 3-24.

[31] Sundaram S, Viswanath PR, Rudrakumar S. Studies on turbulent drag reduction on a NACA 0012 airfoil using riblets. National Aerospace Laboratories Report PD-EA9401, India, 1994.

[32] Sundaram S, Viswanath PR, Rudrakumar S. Viscous drag reduction using riblets on a NACA 0012 airfoil to moderate incidence. AIAA J 1996;34(4):676-82.

[33] Subashchandar N, Rajeev K, Sundaram S. Drag reduction due to riblets on NACA 0012 airfoil at higher angles of attack. National Aerospace Laboratories Report PD-EA9504, India, 1995.

[34] Subashchandar N, Rajeev K, Sundaram S. Drag reduction due to riblets on a GAW(2) airfoil. National Aerospace Laboratories Report PD-EA-9601, India, 1996.

[35] Subashchandar N, Rajeev K, Sundaram S. Drag reduction due to riblets on a GAW(2) airfoil. J Aircr 1999;36(5):890-2.
[36] Sundaram S, Viswanath PR, Subashchandar N. Studies on drag reduction using riblets on an infinite swept wing. National Aerospace Laboratories Report PD-EA-9802, India, 1998.

[37] Sundaram S, Viswanath PR, Subashchandar N. Viscous drag reduction using riblets on a swept wing. AIAA J 1999;37(7):851-6.

[38] Viswanath PR. Riblets on airfoils and wings: a review. AIAA Paper 99-3402, 1999.

[39] Choi KS. Effect of longitudinal pressure gradient on turbulent drag reduction with riblets. In: Coustols E, editor. Turbulence control by passive means. Dordrecht, Netherlands: Kluwer Academic, 1990. p. 109-21.

[40] Caram JM, Ahmed A. Effects of riblets on turbulence in the wake of an airfoil. AIAA 1991;29(11):1769-70.

[41] Desai SS, Kiske S. A computer program to calculate turbulent boundary layer and wakes in compressible flow with arbitrary pressure gradient based on Greens lagentrainment method. Ruhr University. Bericht No. 89/ 1982, Bochum, Germany, 1982.

[42] Debisschop JR, Nieuwstadt FTM. Turbulent boundary layer in an adverse pressure gradient: effectiveness of riblets. AIAA J 1996;34(5):932-7.

[43] Pulles CJA, Krishna Prasad K, Nieuwstadt FTM. Turbulence measurements over longitudinal microgrooved surfaces. Appl Sci Res 1989;46:197-208.

[44] Choi H, Moin P, Kim J. Direct numerical simulation of turbulent flow over riblets. J Fluid Mech 1993;255:503-39.

[45] Benhalilou M, Anseimet F, Fulachier L. Conditional Reynolds stress on a v-grooved surface. Phys Fluids 1994;6(6):2101-17.

[46] Coustols E. Performance of internal manipulators in subsonic three-dimensional flows. In: Choi KS, editor. Recent developments in turbulence management. Dordrecht, Netherlands: Kluwer Academic, 1991. p. 43-64.

[47] Robinson SK. Effects of riblets on turbulence in a supersonic boundary layer. AIAA Paper 88-2526, 1988.

[48] Gaudet L. Properties of riblets at supersonic speed. Appl Sci Res 1989;46:245-54.

[49] Coustols E, Cousteix J. Performances of riblets in the supersonic regime. AIAA J 1994;32(2):431-3.

[50] Zuniga FA, Anderson BT, Bertelrud A. Flight test results of riblets at supersonic speeds. NASA Tech. Memo 4387, 1992.

[51] Nash JF. A discussion of two-dimensional turbulent base flows. Aeronautical Research Council Research Memoranda 3468, UK, 1965.

[52] Chapman DR. An analysis of base pressure at supersonic velocities and comparison with experiment. NACA Report 1051, 1951.

[53] Korst HH. A theory of base pressure in transonic and supersonic flow. J Appl Mech 1956;23:593-600.

[54] Channaraju, Viswanath PR. Base drag reduction caused by riblets on a GAW-2 airfoil. J Aircr 1998;35(6):988-92.

[55] Lynch FT, Klinge MD. Some practical aspects of viscous drag reduction concepts. SAE Technical Paper 912129, 1991.

[56] Wilkinson SP, Anders JB, Lazos BS, Bushnell DM. Turbulent drag reduction research at NASA Langleyprogress and plans. Proceedings of International Conference on Turbulent Drag Reduction by Passive Means. London: Royal Aeronautical Society, 1987. 
[57] Bechert DW. Experiments on three-dimensional riblets. Proceedings of International Conference on Turbulent Drag Reduction by Passive Means. London: Royal Aeronautical Society, 1987.

[58] Pollard A. Passive and active control of nearwall turbulence. Prog Aerosp Sci. 1997;33(11/12): 689-708.

[59] Bechert DW, Bruse M, Hage W. Experiments with threedimensional riblets as an idealised model of shark skin. Expt Fluids 2000;28:403-12.
[60] Launder BE, Li SP. The prediction of riblet behaviour with a Low-Reynolds number $k-\varepsilon$ model. Aeronaut $\mathrm{J}$ 1992;96:351-5.

[61] Pollard A, Savill AM, Tullis S, Wang X. Simulating turbulent flow over thin element and flat valley v-shaped riblets. AIAA J 1996;341(11):2261-8.

[62] Pollard A. Riblets and other methods of controlling nearwall turbulence. In: Choi KS, Prasad KK, Truong TV, editors. Emerging techniques in drag reduction. UK: Mechanical Engineering Publications, 1996, p. 45-76. 